\title{
Computationally Assisted Lead Optimization of Novel Potent and Selective MAO-B Inhibitors
}

\author{
Vedanjali Gogineni ${ }^{1,2}$, Manal A. Nael ${ }^{3,4,+}$, Narayan D. Chaurasiya ${ }^{5,6,+}$, Khaled M. Elokely ${ }^{3,4} \mathbb{D}_{\text {, }}$ \\ Christopher R. McCurdy 1,7, John M. Rimoldi ${ }^{1}$, Stephen J. Cutler 1,8, Babu L. Tekwani ${ }^{5,6, *(D)}$ \\ and Francisco León $1,8, *$ (D)
}

\section{check for} updates

Citation: Gogineni, V.; Nael, M.A.; Chaurasiya, N.D.; Elokely, K.M.; McCurdy, C.R.; Rimoldi, J.M.; Cutler, S.J.; Tekwani, B.L.; León, F. Computationally Assisted Lead Optimization of Novel Potent and Selective MAO-B Inhibitors. Biomedicines 2021, 9, 1304. https:// doi.org/10.3390/biomedicines9101304

Academic Editors: Leonardo Caputo, Laura Quintieri and Orazio Nicolotti

Received: 9 August 2021

Accepted: 18 September 2021

Published: 24 September 2021

Publisher's Note: MDPI stays neutral with regard to jurisdictional claims in published maps and institutional affiliations.

Copyright: (c) 2021 by the authors. Licensee MDPI, Basel, Switzerland. This article is an open access article distributed under the terms and conditions of the Creative Commons Attribution (CC BY) license (https:/ / creativecommons.org/licenses/by/ $4.0 /)$.
1 Department of BioMolecular Sciences, Division of Medicinal Chemistry, University of Mississippi, Oxford, MS 38677, USA; gogineni@musc.edu (V.G.); cmccurdy@cop.ufl.edu (C.R.M.); jrimoldi@olemiss.edu (J.M.R.); sjcutler@cop.sc.edu (S.J.C.)

2 Department of Drug Discovery, Biomedical Sciences and Public Health, College of Pharmacy, Medical University of South Carolina, Charleston, SC 29425, USA

3 Department of Chemistry, Institute for Computational Molecular Science, Temple University, Philadelphia, PA 19122, USA; manal.nael@temple.edu (M.A.N.); kelokely@temple.edu (K.M.E.)

4 Department of Pharmaceutical Chemistry, Faculty of Pharmacy, Tanta University, Tanta 31527, Egypt

5 Division of Drug Discovery, Southern Research, Birmingham, AL 35205, USA; nchaurasiya@southernresearch.org

6 National Center for Natural Products Research, Research Institute of Pharmaceutical Sciences, University of Mississippi, Oxford, MS 38677, USA

7 Department of Medicinal Chemistry, College of Pharmacy, University of Florida, Gainesville, FL 32610, USA

8 Department of Drug Discovery and Biomedical Sciences, College of Pharmacy, University of South Carolina, Columbia, SC 29208, USA

* Correspondence: btekwani@southernresearch.org (B.L.T.); jleon@mailbox.sc.edu (F.L.)

$+\quad$ These authors contributed equally to this study.

Abstract: A series of dietary flavonoid acacetin 7-O-methyl ether derivatives were computationally designed aiming to improve the selectivity and potency profiles against monoamine oxidase (MAO) B. The designed compounds were evaluated for their potential to inhibit human MAO-A and -B. Compounds 1c, 2c, 3c, and 4c were the most potent with a Ki of 37 to $68 \mathrm{nM}$ against MAO-B. Compounds 1c-4c displayed more than a thousand-fold selectivity index towards MAO-B compared with MAO-A. Moreover, compounds $\mathbf{1 c}$ and $\mathbf{2 c}$ showed reversible inhibition of MAO-B. These results provide a basis for further studies on the potential application of these modified flavonoids for the treatment of Parkinson's Disease and other neurological disorders.

Keywords: flavonoids; Parkinson's Disease; monoamine oxidases A and B; acacetin; docking

\section{Introduction}

Parkinson's Disease (PD) is one of the most prevalent neurodegenerative disorders [1], affecting over four million people worldwide. The causes of PD remain unknown. However, the disease is known to arise from interaction between environmental and genetic factors, resulting in progressive degeneration of neurons in the brain. Despite decades of research, the molecular pathways involved in neurodegeneration, the nature of the interaction, and the identity of the factors are poorly understood [2]. PD is characterized by the progressive loss of dopaminergic neurons. Most of the PD cases are sporadic, but rare familial forms have also been recognized. The common pathways underlying the pathogenesis of PD include oxidative stress, mitochondrial quality control, and protein degradation processes. Understanding the possible reasons behind these common processes provides various targets, which are therapeutically relevant to the discovery of disease-modifying treatments [1].

The etiology of PD remains obscure, but oxidative stress is thought to play a significant role in dopaminergic neurotoxicity. At the cellular level, PD is associated with 
excessive production of reactive oxygen species (ROS), resulting in metabolic alteration of catecholamine, the mitochondrial electron-transporter chain (METC), or enhancement of the deposition of iron in the substantia nigra pars compacta (SNpc) [3]. Recently, special focus has been directed to the role of oxidative stress in neurological abnormalities, including PD. Excessive production of ROS has been considered to be a significant cause of neuronal death [4]. The most effective pharmacological treatment to date is levodopa-dopamine substitution therapy. Recently, attention has been shifted towards the enzyme monoamine oxidase $\mathrm{B}$ (MAO-B) as a secondary drug target in PD [5].

MAO-B is one of the two subtypes of the monoamine oxidases (MAO-A and MAO-B). It is a major monoamine-metabolizing enzyme that is known to oxidize the neurotransmitter dopamine, along with other amines. MAO-B is primarily localized in astrocytes, while MAO-A is largely located in the neurons of the brain [5]. Selective, irreversible MAO-B inhibitors are devoid of the severe side effect called the "cheese effect" resulting from the non-selective MAOs that potentiate the effects of tyramine. Since MAO-B is significantly involved in the degradation of dopamine, it is considered to be a first-line therapy for PD [6]. Selegiline [5], rasagiline [5], and safinamide [7] are the only approved MAO-B inhibitors used in the treatment of PD [5-8]. Selegiline and rasagiline are examples of irreversible MAO-B inhibitors [8], while safinamide is a potent reversible MAO-B inhibitor [6]. Therefore, there is a need to develop novel selective MAO-B inhibitors as PD drugs.

Our previous research on the Central American medicinal plant, Calea urticifolia, yielded acacetin, a prominent dietary flavonoid $[9,10]$ as a bioactive compound using bioassay-guided fractionation [9]. Acacetin exhibited good inhibitory activities against MAO-A $(0.121 \mu \mathrm{M})$ and -B $(0.049 \mu \mathrm{M})$. Later, acacetin 7-O-methyl ether proved to be a selective MAO-B inhibitor with a selectivity index (SI) of 505-fold for MAO A/B [11], which inspired further exploration of new MAO-B inhibitors using acacetin 7-O-methyl ether as the lead compound. Flavonoids are known for their admirable safety profile with no known notable adverse effects. Flavonoids possess various pharmacological properties, including anticancer, antioxidant, antimicrobial, cardioprotective, anti-inflammatory, and hepatoprotective activity [12].

In the current study, a series of acacetin 7-O-methyl ether derivatives were computationally designed using fragment-based drug design [13], synthesized, and evaluated as monoamine oxidase B inhibitors. Furthermore, molecular modeling studies were performed to understand the binding interactions.

\section{Materials and Methods}

\subsection{General}

${ }^{1} \mathrm{H}$ and ${ }^{13} \mathrm{C}$ NMR spectra were obtained using Bruker model AMX 400 and 500 NMR spectrometers operating at 400 and $500 \mathrm{MHz}$ in ${ }^{1} \mathrm{H}$ and 100 and $125 \mathrm{MHz}$ in ${ }^{13} \mathrm{C}$, respectively. The chemical shift values were reported from tetramethylsilane (TMS) in parts per million (ppm) using known solvent chemical shifts. Standard pulse sequences were used for DEPT, COSY, HSQC, HMBC, NOESY, and TOCSY. Coupling constants are documented in hertz $(\mathrm{Hz})$. The high-resolution mass spectra (HRMS) were recorded on a Waters Micromass QTof Micro mass spectrometer with a lock spray source. The mass spectra (MS) were recorded on a WATERS ACQUITY Ultra Performance LC with a ZQ detector in ESI mode. If needed, the purity was determined using high-performance liquid chromatography (HPLC). The purity of all the final compounds was greater than $95 \%$. Column chromatography was carried out on Sephadex LH-20 (GE Healthcare, Uppsala, Sweden) and silica gel (70-230 mesh, Merck, Billerica, MA, USA). The fractions from column chromatography were monitored using TLC (silica gel 60 F254, Merck, Billerica, MA, USA). Preparative TLC was carried out with silica gel 60 PF254 +366 plates $(20 \times 20 \mathrm{~cm}, 1 \mathrm{~mm}$ thick, Analtech, Newark, DE, USA). Human recombinant monoamine oxidase A and monoamine oxidase $B$ enzymes were obtained from BD Biosciences (Bedford, MA, USA). Kynuramine, clorgyline, deprenyl, acacetin, and DMSO were purchased from Sigma Chemical (St. Louis, MO, USA). All the acacetin 7-O-methyl ether analogs were synthesized in the Department of 
BioMolecular Sciences, Division of Medicinal Chemistry, School of Pharmacy, University of Mississippi, Oxford, MS, USA.

\subsection{Synthesis of Derivatives}

\subsubsection{Procedure for Preparation of Compounds $1-4$}

Synthesis of (E) 4-Propyloxy-4', 6'-Dimethoxy-2'-Hydroxychalcone (1a)

IUPAC.: (E)-1-(2-Hydroxy-4,6-dimethoxyphenyl)-3-(4-propoxyphenyl)prop-2-en-1-one. A mixture of equimolar amounts of $2^{\prime}$-hydroxy- $4^{\prime}, 6^{\prime}$-dimethoxyacetophenone $(300 \mathrm{mg}, 1.53 \mathrm{mmol})$ and 4- $n$-propoxybenzaldehyde $(251 \mathrm{mg}, 1.53 \mathrm{mmol}$ ) was taken in a round-bottomed flask (RBF) and $10 \mathrm{~mL}$ of $50 \% \mathrm{NaOH}$ in ethanol for $16 \mathrm{~h}$ at rt. The resulting yellow precipitate was filtered and washed with $\mathrm{Hex}$ and $\mathrm{CH}_{2} \mathrm{Cl}_{2}$ to yield $\mathbf{1 a}(342 \mathrm{mg}, 65 \%) .{ }^{1} \mathrm{H} \mathrm{NMR}\left(400 \mathrm{MHz}, \mathrm{CDCl}_{3}\right) \delta_{\mathrm{H}}$ $14.41\left(\mathrm{~s}, \mathrm{C}-2^{\prime}-\mathrm{OH}\right), 7.79(\mathrm{~s} \mathrm{br}, 2 \mathrm{H}, \mathrm{H}-\alpha$ and $\mathrm{H}-\beta), 7.55(\mathrm{~d}, J=8.5 \mathrm{~Hz}, 1 \mathrm{H}, \mathrm{H}-2$ and H-6), $6.91(\mathrm{~d}$, $J=8.5 \mathrm{~Hz}, 2 \mathrm{H}, \mathrm{H}-3$ and $\mathrm{H}-5), 6.10\left(\mathrm{~d}, J=1.8 \mathrm{~Hz}, 1 \mathrm{H}, \mathrm{H}-3^{\prime}\right), 5.96\left(\mathrm{~d}, J=1.8 \mathrm{~Hz}, 1 \mathrm{H}, \mathrm{H}-5^{\prime}\right), 3.97(\mathrm{t}$, $\left.J=6.5,2 \mathrm{H}, \mathrm{H}_{2}-1^{\prime \prime}\right), 3.93\left(\mathrm{~s}, 3 \mathrm{H}, \mathrm{OCH}_{3}\right), 3.85\left(\mathrm{~s}, 3 \mathrm{H}, \mathrm{OCH}_{3}\right), 1.83\left(\mathrm{dt}, J=6.5,7.4 \mathrm{~Hz}, 2 \mathrm{H}, \mathrm{H}_{2}-2^{\prime \prime}\right)$, $1.05\left(\mathrm{t}, J=7.4 \mathrm{~Hz}, 3 \mathrm{H}, \mathrm{CH}_{3}-3^{\prime \prime}\right) .{ }^{13} \mathrm{C}$ NMR $\left(100 \mathrm{MHz}, \mathrm{CDCl}_{3}\right) \delta_{\mathrm{C}} 192.6(\mathrm{C}=\mathrm{O}), 168.3\left(\mathrm{C}-2^{\prime}\right), 166.0$ $\left(\mathrm{C}-4^{\prime}\right), 162.4\left(\mathrm{C}-6^{\prime}\right), 161.0(\mathrm{C}-4), 142.6(\mathrm{C}-\beta), 130.1$ (C-2 and C-6), 128.1 (C-1), 124.9 (C- $\left.\alpha\right), 114.8$ (C-3 and C-5), $106.3\left(\mathrm{C}-1^{\prime}\right), 93.8\left(\mathrm{C}-3^{\prime}\right), 91.2\left(\mathrm{C}-5^{\prime}\right), 69.6\left(\mathrm{C}-1^{\prime \prime}\right), 55.8\left(\mathrm{OCH}_{3}\right), 55.5\left(\mathrm{OCH}_{3}\right), 22.5$ (C-2"), 10.5 (C-3"). HRESIMS $m / z 343.0897[\mathrm{M}+\mathrm{H}]^{+}$(calcd $\left.\mathrm{C}_{20} \mathrm{H}_{22} \mathrm{O}_{5} 342.1467\right)$.

Synthesis of 5,7-Dimethoxy-4'-Propyloxyflavone (1b)

IUPAC.: 5,7-Dimethoxy-2-(4-propoxyphenyl)-4H-chromen-4-one. The chalcone 1a (200 mg, $0.584 \mathrm{mmol}$ ) was treated with $3-4 \mathrm{~mol} \%$ of iodine crystals with a minimal amount of DMSO at $140{ }^{\circ} \mathrm{C}$ for $4-6 \mathrm{~h}$. The resulting white precipitate was extracted with $\mathrm{CH}_{2} \mathrm{Cl}_{2}$ and was removed by filtration. The filtrate was transferred into a separatory funnel where the layers were separated as aqueous and organic. The organic layer was washed with sodium thiosulfate $\left(\mathrm{Na}_{2} \mathrm{~S}_{2} \mathrm{O}_{3}\right)$, dried with sodium sulfate $\left(\mathrm{Na}_{2} \mathrm{SO}_{4}\right)$, and concentrated. The intermediate flavonoid $\mathbf{1 b}$ was then purified in a silica column using $100 \% \mathrm{CH}_{2} \mathrm{Cl}_{2}, 50: 1$ $\mathrm{CH}_{2} \mathrm{Cl}_{2}-\mathrm{MeOH}$, 9:1 $\mathrm{CH}_{2} \mathrm{Cl}_{2}-\mathrm{MeOH}, 1: 1 \mathrm{CH}_{2} \mathrm{Cl}_{2}-\mathrm{MeOH}$, and 100\% MeOH (128 mg, 64\%). ${ }^{1} \mathrm{H}$ NMR $\left(400 \mathrm{MHz}, \mathrm{CDCl}_{3}\right) \delta_{\mathrm{H}} 7.80\left(\mathrm{~d}, J=8.9 \mathrm{~Hz}, 2 \mathrm{H}, \mathrm{H}-2^{\prime}\right.$ and $\left.\mathrm{H}-6^{\prime}\right), 6.98(\mathrm{~d}, J=8.9 \mathrm{~Hz}$, $2 \mathrm{H}, \mathrm{H}-3^{\prime}$ and $\left.\mathrm{H}-5^{\prime}\right), 6.59(\mathrm{~s}, 1 \mathrm{H}, \mathrm{H}-3), 6.57(\mathrm{~d}, J=2.3 \mathrm{~Hz}, 1 \mathrm{H}, \mathrm{H}-6), 6.37(\mathrm{~d}, J=2.3 \mathrm{~Hz}, 1 \mathrm{H}$, $\mathrm{H}-8), 3.99\left(\mathrm{t}, J=6.6 \mathrm{~Hz}, 2 \mathrm{H}, \mathrm{H}_{2}-1^{\prime \prime}\right), 3.96\left(\mathrm{~s}, \mathrm{OCH}_{3}\right), 3.91\left(\mathrm{~s}, \mathrm{OCH}_{3}\right), 1.84(\mathrm{dt}, J=6.5,7.4 \mathrm{~Hz}$, $\left.2 \mathrm{H}, \mathrm{H}_{2}-2^{\prime \prime}\right), 1.06\left(\mathrm{t}, J=7.4 \mathrm{~Hz}, 3 \mathrm{H} \mathrm{CH} \mathrm{CH}_{3}-3^{\prime \prime}\right) .{ }^{13} \mathrm{C} \mathrm{NMR}\left(100 \mathrm{MHz}, \mathrm{CDCl}_{3}\right) \delta_{\mathrm{C}} 177.7(\mathrm{C}-4)$, 163.9 (C-2), 161.6 (C-5), 160.9 (C-4'), 160.7 (C-9), 159.8 (C-7), 127.5 (C-2' and C-6'), 123.5 $\left(\mathrm{C}-1^{\prime}\right), 114.8\left(\mathrm{C}-3^{\prime}\right.$ and $\left.\mathrm{C}-5^{\prime}\right), 109.2(\mathrm{C}-10), 107.6$ (C-3), 96.0 (C-8), 92.8 (C-6), 69.7 (C-1"), $56.4\left(\mathrm{OCH}_{3}\right), 55.7\left(\mathrm{OCH}_{3}\right), 22.5\left(\mathrm{C}-2^{\prime \prime}\right), 10.5(\mathrm{C}-3 ")$. HRESIMS $m / z 341.0738[\mathrm{M}+\mathrm{H}]^{+}$(calcd $\left.\mathrm{C}_{20} \mathrm{H}_{20} \mathrm{O}_{5} 340.1311\right)$.

Synthesis of 7-Methoxy-4'-Propyloxy-5-Hydroxyflavone (1c)

IUPAC.: 5-Hydroxy-7-methoxy-2-(4-propoxyphenyl)-4H-chromen-4-one. The intermediate $\mathbf{1 b}(128 \mathrm{mg}, 0.377 \mathrm{mmol})$ was treated with $1 \mathrm{~N}$ boron tribromide $(189 \mathrm{mg}, 0.754 \mathrm{mmol})$ in the presence of $\mathrm{CH}_{2} \mathrm{Cl}_{2}$ at $\mathrm{rt}$ for 1-3 $\mathrm{h}$. The reactant solution was diluted with 10:1 $\mathrm{CH}_{2} \mathrm{Cl}_{2}: \mathrm{MeOH}$ and then washed with brine and water. $\mathrm{Na}_{2} \mathrm{SO}_{4}$ was added to the solution and left overnight. The solution was then filtered, dried, and concentrated. The flavonoid 1c was purified in a silica column using 30:1 $\mathrm{CH}_{2} \mathrm{Cl}_{2}-\mathrm{MeOH}(35 \mathrm{mg}, 29 \%)$. ${ }^{1} \mathrm{H}$ NMR $\left(400 \mathrm{MHz}, \mathrm{CDCl}_{3}\right) \delta_{\mathrm{H}} 12.83(\mathrm{~s}, \mathrm{C}-5-\mathrm{OH}), 7.82\left(\mathrm{~d}, J=8.9 \mathrm{~Hz}, 2 \mathrm{H}, \mathrm{H}-2^{\prime}\right.$ and $\left.\mathrm{H}-6^{\prime}\right), 7.00(\mathrm{~d}$, $J=8.9 \mathrm{~Hz}, 2 \mathrm{H}, \mathrm{H}-3^{\prime}$ and $\left.\mathrm{H}-5^{\prime}\right), 6.56(\mathrm{~s}, 1 \mathrm{H}, \mathrm{H}-3), 6.47(\mathrm{~d}, J=2.2 \mathrm{~Hz}, 1 \mathrm{H}, \mathrm{H}-6), 6.35(\mathrm{~d}$, $J=2.2 \mathrm{~Hz}, 1 \mathrm{H}, \mathrm{H}-8), 4.00\left(\mathrm{t}, J=6.6 \mathrm{~Hz}, 2 \mathrm{H}, \mathrm{H}_{2}-1^{\prime \prime}\right), 3.88\left(\mathrm{~s}, \mathrm{OCH}_{3}\right), 1.86(\mathrm{ddd}, J=6.6,7.4 \mathrm{~Hz}$, $\left.2 \mathrm{H}, \mathrm{H}_{2}-2^{\prime \prime}\right), 1.08\left(\mathrm{t}, J=7.4 \mathrm{~Hz}, 3 \mathrm{H}, \mathrm{CH}_{3}-3^{\prime \prime}\right) .{ }^{13} \mathrm{C} \mathrm{NMR}\left(100 \mathrm{MHz}, \mathrm{CDCl}_{3}\right) \delta_{\mathrm{C}} 182.4(\mathrm{C}-4)$, 165.4 (C-7), 164.0 (C-2), 162.2 (C-4'), 162.1 (C-5), $157.6(\mathrm{C}-9), 127.7\left(\mathrm{C}-2^{\prime}\right.$ and C-6' $\left.{ }^{\prime}\right), 123.5$ $\left(\mathrm{C}-1^{\prime}\right), 115.0\left(\mathrm{C}-3^{\prime}\right.$ and $\left.\mathrm{C}-5^{\prime}\right), 105.5$ (C-10), 104.2 (C-3), 98.0 (C-8), 92.5 (C-6), 69.8 (C-1"), $55.8\left(\mathrm{OCH}_{3}\right), 22.5\left(\mathrm{C}-2^{\prime \prime}\right), 10.5\left(\mathrm{C}-3^{\prime \prime}\right)$. HRESIMS $m / z 327.1038[\mathrm{M}+\mathrm{H}]^{+}\left(\operatorname{calcd} \mathrm{C}_{19} \mathrm{H}_{18} \mathrm{O}_{5}\right.$ 326.1154). 
Synthesis of (E) 4-Isopropyloxy-4', $6^{\prime}$-Dimethoxy-2'-Hydroxychalcone (2a)

IUPAC.: (E)-1-(2-Hydroxy-4,6-dimethoxyphenyl)-3-(4-isopropoxyphenyl)prop-2-en1-one. The procedure for the preparation of the chalcone $\mathbf{2 a}$ is similar to that for the preparation of the chalcone 1a except for the use of 4-isopropoxybenzaldehyde ( $251 \mathrm{mg}$, $1.53 \mathrm{mmol})$. The chalcone $2 \mathrm{a}$ was purified in a silica column using 4:1 Hex-EtOAc, 3:1 Hex-EtOAc, 4:1 EtOAc-Hex, 100\% EtOAc, and 100\% MeOH (411 mg, 79\%). ${ }^{1} \mathrm{H}$ NMR $\left(400 \mathrm{MHz}, \mathrm{CDCl}_{3}\right) \delta_{\mathrm{H}} 14.43\left(\mathrm{~s}, \mathrm{C}-2^{\prime}-\mathrm{OH}\right), 7.80(\mathrm{~s} \mathrm{br}, 2 \mathrm{H}, \mathrm{H}-\alpha$ and $\mathrm{H}-\beta), 7.55(\mathrm{~d}, J=8.7 \mathrm{~Hz}$, 2H, H-2 and H-6), 6.91 (d, $J=8.7 \mathrm{~Hz}, 2 \mathrm{H}, \mathrm{H}-3$ and $\mathrm{H}-5), 6.12\left(\mathrm{~d}, J=2.3,1 \mathrm{H}, \mathrm{H}-3^{\prime}\right), 5.97$ $\left(\mathrm{d}, J=2.3,1 \mathrm{H}, \mathrm{H}-5^{\prime}\right), 4.62\left(\mathrm{sept}, J=6.0 \mathrm{~Hz}, 1 \mathrm{H}, \mathrm{H}-1^{\prime \prime}\right), 3.93\left(\mathrm{~s}, 3 \mathrm{H}, \mathrm{OCH}_{3}\right), 3.84(\mathrm{~s}, 3 \mathrm{H}$, $\left.\mathrm{OCH}_{3}\right), 1.37\left(\mathrm{~d}, J=6.0 \mathrm{~Hz}, 6 \mathrm{H}, \mathrm{CH}_{3}-2\right.$ " and $\left.\mathrm{CH}_{3}-3^{\prime \prime}\right) .{ }^{13} \mathrm{C} \mathrm{NMR}\left(100 \mathrm{MHz}, \mathrm{CDCl}_{3}\right) \delta_{\mathrm{C}} 192.6$ $(\mathrm{C}=\mathrm{O}), 168.3\left(\mathrm{C}-2^{\prime}\right), 166.0\left(\mathrm{C}-4^{\prime}\right), 162.4\left(\mathrm{C}-6^{\prime}\right), 159.8(\mathrm{C}-4), 142.6(\mathrm{C}-\beta), 130.1(\mathrm{C}-2$ and $\mathrm{C}-6)$, 127.9 (C-1), $124.9(\mathrm{C}-\alpha), 115.9$ (C-3 and C-5), $106.4\left(\mathrm{C}-1^{\prime}\right), 93.8\left(\mathrm{C}-3^{\prime}\right), 91.2\left(\mathrm{C}-5^{\prime}\right), 70.0\left(\mathrm{C}-1^{\prime \prime}\right)$, $55.8\left(\mathrm{OCH}_{3}\right), 55.6\left(\mathrm{OCH}_{3}\right), 22.0\left(\mathrm{C}-2^{\prime \prime}\right.$ and $\left.\mathrm{C}-3 "\right)$. HRESIMS $m / z 343.0876[\mathrm{M}+\mathrm{H}]^{+}$(calcd $\left.\mathrm{C}_{20} \mathrm{H}_{22} \mathrm{O}_{5} 342.1467\right)$.

Synthesis of 5,7-Dimethoxy-4'-Isopropyloxyflavone (2b)

IUPAC.: 2-(4-Isopropoxyphenyl)-5,7-dimethoxy-4H-chromen-4-one. This procedure is similar to that for the preparation of the intermediate flavonoid $\mathbf{1 b}$. The intermediate flavonoid $\mathbf{2} \mathbf{b}$ was purified in a silica column using 1:1 Hex-EtOAc, 100\% EtOAc, 20:1 EtOAc-MeOH, and $100 \% \mathrm{MeOH}(78 \mathrm{mg}, 52 \%) .{ }^{1} \mathrm{H}$ NMR $\left(400 \mathrm{MHz}, \mathrm{CDCl}_{3}\right) \delta_{\mathrm{H}} 7.78(\mathrm{~d}$, $J=8.9 \mathrm{~Hz}, 2 \mathrm{H}, \mathrm{H}-2^{\prime}$ and $\left.\mathrm{H}-6^{\prime}\right), 6.95\left(\mathrm{~d}, J=8.9,2 \mathrm{H}, \mathrm{H}-3^{\prime}\right.$ and $\left.\mathrm{H}-5^{\prime}\right), 6.56(\mathrm{~s}, 1 \mathrm{H}, \mathrm{H}-3), 6.53$ (d, $J=2.3,1 \mathrm{H}, \mathrm{H}-6), 6.34$ (d, $J=2.3,1 \mathrm{H}, \mathrm{H}-8), 4.62$ (sept, $J=6.0 \mathrm{~Hz}, 1 \mathrm{H}, \mathrm{H}-1 "), 3.93$ (s, $\left.3 \mathrm{H}, \mathrm{OCH}_{3}\right), 3.89\left(\mathrm{~s}, 3 \mathrm{H}, \mathrm{OCH}_{3}\right), 1.36\left(\mathrm{~d}, J=6.0 \mathrm{~Hz}, 6 \mathrm{H}, \mathrm{CH}_{3}-2\right.$ " and $\mathrm{CH}_{3}-3$ " $) .{ }^{13} \mathrm{C} \mathrm{NMR}$ $\left(100 \mathrm{MHz}, \mathrm{CDCl}_{3}\right) \delta_{\mathrm{C}} 177.6$ (C-4), 163.8 (C-2), 160.8 (C-5), 160.7 (C-4'), 160.5 (C-9), 159.8 (C-7), 127.6 (C-2' and C-6'), $123.3\left(\mathrm{C}-1^{\prime}\right), 115.8\left(\mathrm{C}-3^{\prime}\right.$ and $\left.\mathrm{C}-5^{\prime}\right), 109.2(\mathrm{C}-3), 109.2(\mathrm{C}-10), 107.5$ (C-3), $96.0(\mathrm{C}-8), 92.8(\mathrm{C}-6), 70.1\left(\mathrm{C}-1{ }^{\prime \prime}\right), 56.4\left(\mathrm{OCH}_{3}\right), 55.7\left(\mathrm{OCH}_{3}\right), 21.9\left(\mathrm{C}-2^{\prime \prime}\right.$ and $\left.\mathrm{C}-3 "\right)$. HRESIMS $m / z 341.0796[\mathrm{M}+\mathrm{H}]^{+}\left(\right.$calcd $\mathrm{C}_{20} \mathrm{H}_{20} \mathrm{O}_{5} 340.1311$ ).

Synthesis of 7-Methoxy-4'-Isopropyloxy-5-Hydroxyflavone (2c)

IUPAC.: 5-Hydroxy-2-(4-isopropoxyphenyl)-7-methoxy-4H-chromen-4-one. This procedure is similar to that for the preparation of the final flavonoid $\mathbf{1 c}$. The final flavonoid $\mathbf{2 c}$ was purified in a silica column using 7:3 Hex-EtOAc and 1:1 Hex-EtOAc $(6 \mathrm{mg}, 10 \%) .{ }^{1} \mathrm{H}$ $\operatorname{NMR}\left(400 \mathrm{MHz}, \mathrm{CDCl}_{3}\right) \delta_{\mathrm{H}} 12.83(\mathrm{~s}, \mathrm{C}-5-\mathrm{OH}), 7.83\left(\mathrm{~d}, J=8.9 \mathrm{~Hz}, 2 \mathrm{H}, \mathrm{H}-2^{\prime}\right.$ and $\left.\mathrm{H}-6^{\prime}\right), 6.99$ $\left(\mathrm{d}, J=8.9 \mathrm{~Hz}, 2 \mathrm{H}, \mathrm{H}-3^{\prime}\right.$ and $\left.\mathrm{H}-5^{\prime}\right), 6.58(\mathrm{~s}, 1 \mathrm{H}, \mathrm{H}-3), 6.49(\mathrm{~d}, J=2.2 \mathrm{~Hz}, 1 \mathrm{H}, \mathrm{H}-6), 6.37(\mathrm{~d}$, $J=2.2 \mathrm{~Hz}, 1 \mathrm{H}, \mathrm{H}-8), 4.66\left(\mathrm{sept}, J=6.0 \mathrm{~Hz}, 1 \mathrm{H}, \mathrm{H}-1^{\prime \prime}\right), 3.89\left(\mathrm{~s}, 3 \mathrm{H}, \mathrm{OCH}_{3}\right), 1.40(\mathrm{~d}, J=6.0 \mathrm{~Hz}$, $6 \mathrm{H}, \mathrm{CH}_{3}-2$ " and $\left.\mathrm{CH}_{3}-3^{\prime \prime}\right) .{ }^{13} \mathrm{C}$ NMR $\left(100 \mathrm{MHz}, \mathrm{CDCl}_{3}\right) \delta_{\mathrm{C}} 182.4(\mathrm{C}-4), 165.4(\mathrm{C}-7), 164.1$ (C-2), 162.2 (C-4'), 161.1 (C-5), 157.3 (C-9), $128.0\left(\mathrm{C}-2^{\prime}\right.$ and C-6'), $123.1\left(\mathrm{C}-1^{\prime}\right), 115.9\left(\mathrm{C}-3^{\prime}\right.$

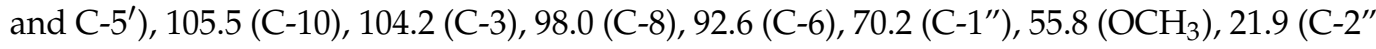
and $\left.\mathrm{C}-3^{\prime \prime}\right)$. HRESIMS $m / z 327.1038[\mathrm{M}+\mathrm{H}]^{+}\left(\right.$calcd $\left.\mathrm{C}_{19} \mathrm{H}_{18} \mathrm{O}_{5} 326.1154\right)$.

Synthesis of (E) 4-Isobutyloxy-4' 6' $^{\prime}$-Dimethoxy-2'-Hydroxychalcone (3a)

IUPAC.: (E)-1-(2-Hydroxy-4,6-dimethoxyphenyl)-3-(4-isobutoxyphenyl)prop-2-en-1one. This procedure is similar to that for the preparation of the chalcone 1a except for the use of 4-isobutoxy benzaldehyde $(273 \mathrm{mg}, 1.53 \mathrm{mmol})$. The chalcone $3 \mathrm{a}$ was purified in a silica column using $\mathrm{CH}_{2} \mathrm{Cl}_{2}(436 \mathrm{mg}, 80 \%) .{ }^{1} \mathrm{H} \mathrm{NMR}\left(500 \mathrm{MHz}, \mathrm{CDCl}_{3}\right) \delta_{\mathrm{H}} 14.45(\mathrm{~s}$, C-2'-OH), $7.82(\mathrm{~s}, \mathrm{br}, 2 \mathrm{H}, \mathrm{H}-\alpha$ and $\mathrm{H}-\beta), 7.57(\mathrm{~d}, J=8.8 \mathrm{~Hz}, 2 \mathrm{H}, \mathrm{H}-2$ and $\mathrm{H}-6), 6.94(\mathrm{~d}$, $J=8.8 \mathrm{~Hz}, 2 \mathrm{H}, \mathrm{H}-3$ and H-5), $6.13\left(\mathrm{~d}, J=2.4 \mathrm{~Hz}, 1 \mathrm{H}, \mathrm{H}-3^{\prime}\right), 5.99\left(\mathrm{~d}, J=2.4 \mathrm{~Hz}, 1 \mathrm{H}, \mathrm{H}-5^{\prime}\right)$, $3.94\left(\mathrm{~s}, 3 \mathrm{H}, \mathrm{OCH}_{3}\right), 3.86\left(\mathrm{~s}, 3 \mathrm{H}, \mathrm{OCH}_{3}\right), 3.79\left(\mathrm{~d}, J=6.6 \mathrm{~Hz}, 2 \mathrm{H}, \mathrm{H}_{2}-1^{\prime \prime}\right), 2.13(\mathrm{sept}, J=6.7 \mathrm{~Hz}$, $1 \mathrm{H}, \mathrm{H}-2 "), 1.06\left(\mathrm{~d}, J=6.7 \mathrm{~Hz}, 6 \mathrm{H}, \mathrm{CH}_{3}-3\right.$ " and $\left.\mathrm{CH}_{3}-4^{\prime \prime}\right) .{ }^{13} \mathrm{C} \mathrm{NMR}\left(125 \mathrm{MHz}, \mathrm{CDCl}_{3}\right) \delta_{\mathrm{C}}$ $192.6(\mathrm{C}=\mathrm{O}), 168.4\left(\mathrm{C}-2^{\prime}\right), 166.0\left(\mathrm{C}-4^{\prime}\right), 162.4\left(\mathrm{C}-6^{\prime}\right), 161.1(\mathrm{C}-4), 142.6(\mathrm{C}-\beta), 130.1(\mathrm{C}-2$ and C-6), $128.0(\mathrm{C}-1), 124.9(\mathrm{C}-\alpha), 114.9$ (C-3 and C-5), $106.4\left(\mathrm{C}-1^{\prime}\right), 93.8\left(\mathrm{C}-3^{\prime}\right), 91.2\left(\mathrm{C}-5^{\prime}\right), 74.5$ $\left(\mathrm{C}-1^{\prime \prime}\right), 55.8\left(\mathrm{OCH}_{3}\right), 55.6\left(\mathrm{OCH}_{3}\right), 28.2\left(\mathrm{C}-2^{\prime \prime}\right), 19.2\left(\mathrm{C}-3^{\prime \prime}\right.$ and $\left.\mathrm{C}-4^{\prime \prime}\right)$. HRESIMS $m / z 357.0610$ $[\mathrm{M}+\mathrm{H}]^{+}\left(\right.$calcd $\left.\mathrm{C}_{21} \mathrm{H}_{24} \mathrm{O}_{5} 356.1624\right)$. 
Synthesis of 5,7-Dimethoxy-4'-Isobutyloxyflavone (3b)

IUPAC.: 2-(4-Isobutoxyphenyl)-5,7-dimethoxy-4H-chromen-4-one. This procedure is similar to that for the preparation of the intermediate flavonoid $\mathbf{1 b}$. The intermediate flavonoid $\mathbf{3} \mathbf{b}$ was purified in a silica column using 1:1 Hex-EtOAc, 8:2 EtOAc-Hex, 100\% EtOAc, 20:1 EtOAc, and 9:1 EtOAc-MeOH (113 mg, 57\%). ${ }^{1} \mathrm{H}$ NMR $\left(400 \mathrm{MHz}, \mathrm{CDCl}_{3}\right)$ $\delta_{\mathrm{H}} 7.73\left(\mathrm{~d}, J=8.6 \mathrm{~Hz}, 2 \mathrm{H}, \mathrm{H}-2^{\prime}\right.$ and $\left.\mathrm{H}-6^{\prime}\right), 6.92\left(\mathrm{~d}, J=8.4 \mathrm{~Hz}, 2 \mathrm{H}, \mathrm{H}-3^{\prime}\right.$ and $\left.\mathrm{H}-5^{\prime}\right), 6.52(\mathrm{~s}$, $1 \mathrm{H}, \mathrm{H}-3), 6.48(\mathrm{~d}, J=1.4 \mathrm{~Hz}, 1 \mathrm{H}, \mathrm{H}-6), 6.29(\mathrm{~d}, J=1.6 \mathrm{~Hz}, 1 \mathrm{H}, \mathrm{H}-8), 3.89\left(\mathrm{~s}, 3 \mathrm{H}, \mathrm{OCH}_{3}\right)$, $3.85\left(\mathrm{~s}, 3 \mathrm{H}, \mathrm{OCH}_{3}\right), 3.73\left(\mathrm{~d}, J=6.5 \mathrm{~Hz}, 2 \mathrm{H}, \mathrm{H}_{2}-1^{\prime \prime}\right), 2.07$ (sept, $\left.J=6.7 \mathrm{~Hz}, 1 \mathrm{H}, \mathrm{H}-2^{\prime \prime}\right), 1.00$ $\left(\mathrm{d}, J=6.7 \mathrm{~Hz}, 6 \mathrm{H}, \mathrm{CH}_{3}-3\right.$ " and $\left.\mathrm{CH}_{3}-44^{\prime \prime}\right) .{ }^{13} \mathrm{C}$ NMR $\left(100 \mathrm{MHz}, \mathrm{CDCl}_{3}\right) \delta_{\mathrm{C}} 177.6(\mathrm{C}-4), 163.8$ (C-2), 161.7 (C-5), 160.7 (C-4' and C-9), 159.7 (C-7), $127.4\left(\mathrm{C}-2^{\prime}\right.$ and C-6' $\left.{ }^{\prime}\right), 123.4\left(\mathrm{C}-1^{\prime}\right), 114.8$ $\left(\mathrm{C}-3^{\prime}\right.$ and $\left.\mathrm{C}-5^{\prime}\right), 109.0(\mathrm{C}-10), 107.4(\mathrm{C}-3), 96.0(\mathrm{C}-8), 92.8(\mathrm{C}-6), 74.5\left(\mathrm{C}-1^{\prime \prime}\right), 56.3\left(\mathrm{OCH}_{3}\right)$, $55.7\left(\mathrm{OCH}_{3}\right), 28.2\left(\mathrm{C}-2^{\prime \prime}\right), 19.2\left(\mathrm{C}-3^{\prime \prime}\right.$ and C-4"). HRESIMS $m / z 355.0958[\mathrm{M}+\mathrm{H}]^{+}$(calcd $\left.\mathrm{C}_{21} \mathrm{H}_{22} \mathrm{O}_{5} 354.1467\right)$.

Synthesis of 7-Methoxy-4'-Isobutyloxy-5-Hydroxyflavone (3c)

IUPAC.: 5-Hydroxy-2-(4-Isobutoxyphenyl)7-methoxy-4H-chromen-4-one. This procedure is similar to that for the preparation of the final flavonoid 1c. The final flavonoid $3 \mathbf{c}$ was purified in a silica column using 7:3 EtOAc-Hex and 100\% EtOAc $(40 \mathrm{mg}, 44 \%) .{ }^{1} \mathrm{H}$ $\operatorname{NMR}\left(400 \mathrm{MHz}, \mathrm{CDCl}_{3}\right) \delta_{\mathrm{H}} 12.79(\mathrm{~s}, \mathrm{C}-5-\mathrm{OH}), 7.81\left(\mathrm{~d}, J=8.9 \mathrm{~Hz}, 2 \mathrm{H}, \mathrm{H}-2^{\prime}\right.$ and $\left.\mathrm{H}-6^{\prime}\right), 7.00$ $\left(\mathrm{d}, J=8.9 \mathrm{~Hz}, 2 \mathrm{H}, \mathrm{H}-3^{\prime}\right.$ and $\left.\mathrm{H}-5^{\prime}\right), 6.56(\mathrm{~s}, 1 \mathrm{H}, \mathrm{H}-3), 6.47(\mathrm{~d}, J=2.2 \mathrm{~Hz}, 1 \mathrm{H}, \mathrm{H}-6), 6.36(\mathrm{~d}$, $J=2.2 \mathrm{~Hz}, 1 \mathrm{H}, \mathrm{H}-8), 3.88\left(\mathrm{~s}, 3 \mathrm{H}, \mathrm{OCH}_{3}\right), 3.80\left(\mathrm{~d}, J=6.6 \mathrm{~Hz}, 2 \mathrm{H}, \mathrm{H}_{2}-1^{\prime \prime}\right), 2.14(\mathrm{sept}, J=6.6 \mathrm{~Hz}$, $\left.1 \mathrm{H}, \mathrm{CH}_{3}-2^{\prime \prime}\right), 1.07\left(\mathrm{~d}, \mathrm{~J}=6.7 \mathrm{~Hz}, 6 \mathrm{H}, \mathrm{CH}_{3}-3^{\prime \prime}\right.$ and $\left.\mathrm{CH}_{3}-4^{\prime \prime}\right) .{ }^{13} \mathrm{C} \mathrm{NMR}\left(100 \mathrm{MHz}, \mathrm{CDCl}_{3}\right) \delta_{\mathrm{C}}$ 182.4 (C-4), 165.4 (C-7), 164.1 (C-2), 162.3 (C-4'), 162.1 (C-5), 157.6 (C-9), 127.9 (C-2' and C-6'), $123.1\left(\mathrm{C}-1^{\prime}\right), 114.9\left(\mathrm{C}-3^{\prime}\right.$ and $\left.\mathrm{C}-5^{\prime}\right), 105.5(\mathrm{C}-10), 104.1$ (C-3), 98.0 (C-8), $92.5(\mathrm{C}-6), 74.6$ $\left(\mathrm{C}-1^{\prime \prime}\right), 55.7\left(\mathrm{OCH}_{3}\right), 28.2\left(\mathrm{C}-2^{\prime \prime}\right), 19.2\left(\mathrm{C}-3^{\prime \prime}\right.$ and C-4"). HRESIMS $\mathrm{m} / z 341.0737[\mathrm{M}+\mathrm{H}]^{+}$ (calcd $\mathrm{C}_{20} \mathrm{H}_{20} \mathrm{O}_{5}$ 340.1311).

Synthesis of (E) 4-Propargyloxy-4',6'-Dimethoxy-2'-Hydroxychalcone (4a)

IUPAC.: (E)-1-(2-Hydroxy-4,6-dimethoxyphenyl)-3-(4-(prop-2-yn-1-yloxy)phenyl)prop2-en-1-one. This procedure is similar to that for the preparation of the chalcone 1a except for the use of 4-(prop-2-ynyloxy)benzaldehyde $(245 \mathrm{mg}, 1.53 \mathrm{mmol})$. The chalcone $4 \mathrm{a}$ was purified in a silica column using $100 \% \mathrm{CH}_{2} \mathrm{Cl}_{2}(326 \mathrm{mg}, 63 \%) .{ }^{1} \mathrm{H} \mathrm{NMR}\left(500 \mathrm{MHz}, \mathrm{CDCl}_{3}\right) \delta_{\mathrm{H}} 14.38$ $\left(\mathrm{s}, \mathrm{C}-2^{\prime}-\mathrm{OH}\right), 7.84(\mathrm{~d}, J=15.6 \mathrm{~Hz}, 1 \mathrm{H}, \mathrm{H}-\beta), 7.79(\mathrm{~d}, J=15.6 \mathrm{~Hz}, 1 \mathrm{H}, \mathrm{H}-\alpha), 7.60(\mathrm{~d}, J=8.8 \mathrm{~Hz}$, $2 \mathrm{H}, \mathrm{H}-2$ and $\mathrm{H}-6), 7.03(\mathrm{~d}, J=8.8 \mathrm{~Hz}, 2 \mathrm{H}, \mathrm{H}-3$ and $\mathrm{H}-5), 6.14\left(\mathrm{~d}, J=2.3 \mathrm{~Hz}, 1 \mathrm{H}, \mathrm{H}-3^{\prime}\right), 5.99(\mathrm{~d}$, $\left.J=2.3 \mathrm{~Hz}, 1 \mathrm{H}, \mathrm{H}-5^{\prime}\right), 4.76\left(\mathrm{~d}, J=2.4 \mathrm{~Hz}, 2 \mathrm{H}, \mathrm{H}_{2}-1^{\prime \prime}\right), 3.94\left(\mathrm{~s}, 3 \mathrm{H}, \mathrm{OCH}_{3}\right), 3.86\left(\mathrm{~s}, 3 \mathrm{H}, \mathrm{OCH}_{3}\right), 2.57$ $\left(\mathrm{t}, J=2.4 \mathrm{~Hz}, 1 \mathrm{H}, \mathrm{H}-3^{\prime \prime}\right) .{ }^{13} \mathrm{C}$ NMR $\left(125 \mathrm{MHz}, \mathrm{CDCl}_{3}\right) \delta_{\mathrm{C}} 192.6(\mathrm{C}=\mathrm{O}), 168.4\left(\mathrm{C}-2^{\prime}\right), 166.1\left(\mathrm{C}-4^{\prime}\right)$, $162.5\left(\mathrm{C}-6^{\prime}\right), 159.1$ (C-4), 142.1 (C- $\beta$ ), 130.0 (C-2 and C-6), 129.2 (C-1), 125.7 (C- $\left.\alpha\right), 115.3$ (C-3 and C-5), 106.4 (C-1'), $93.8\left(\mathrm{C}-3^{\prime}\right), 91.3\left(\mathrm{C}-5^{\prime}\right), 78.1\left(\mathrm{C}-2^{\prime \prime}\right), 75.9\left(\mathrm{C}-3^{\prime \prime}\right), 55.9\left(2 \mathrm{C}, \mathrm{OCH}_{3}, \mathrm{C}-1^{\prime \prime}\right), 55.6$ $\left(\mathrm{OCH}_{3}\right)$. HRESIMS $m / z 339.0599[\mathrm{M}+\mathrm{H}]^{+}\left(\right.$calcd $\mathrm{C}_{20} \mathrm{H}_{18} \mathrm{O}_{5}$ 338.1154).

Synthesis of 5,7-Dimethoxy-4'-Propargyloxyflavone (4b)

IUPAC.: 5,7-Dimethoxy-2-(4-(prop-2-yn-1-yloxy)phenyl)-4H-chromen-4-one. This procedure is similar to that for the preparation of the intermediate flavonoid $\mathbf{1 b}$. The intermediate flavonoid $\mathbf{4 b}$ was purified in a silica column using 1:1 Hex-EtOAc, 100\% EtOAc, 20:1 EtOAc-MeOH, 9:1 EtOAc-MeOH, 1:1 EtOAc-MeOH, and 100\% MeOH (87 mg, $54 \%) .{ }^{1} \mathrm{H} \mathrm{NMR}\left(400 \mathrm{MHz}, \mathrm{CDCl}_{3}\right) \delta_{\mathrm{H}} 7.82\left(\mathrm{~d}, J=8.9 \mathrm{~Hz}, 2 \mathrm{H}, \mathrm{H}-2^{\prime}\right.$ and $\left.\mathrm{H}-6^{\prime}\right), 7.07(\mathrm{~d}$, $J=8.9 \mathrm{~Hz}, 2 \mathrm{H}, \mathrm{H}-3^{\prime}$ and $\left.\mathrm{H}^{-} 5^{\prime}\right), 6.58(\mathrm{~s}, 1 \mathrm{H}, \mathrm{H}-3), 6.54(\mathrm{~d}, J=2.3 \mathrm{~Hz}, 1 \mathrm{H}, \mathrm{H}-6), 6.36(\mathrm{~d}$, $J=2.3 \mathrm{~Hz}, 1 \mathrm{H}, \mathrm{H}-8), 4.76\left(\mathrm{~d}, J=2.4 \mathrm{~Hz}, 2 \mathrm{H}, \mathrm{H}_{2}-1^{\prime \prime}\right), 3.94\left(\mathrm{~s}, 3 \mathrm{H}, \mathrm{OCH}_{3}\right), 3.90\left(\mathrm{~s}, 3 \mathrm{H}, \mathrm{OCH}_{3}\right)$, $2.57\left(\mathrm{t}, J=2.4 \mathrm{~Hz}, 1 \mathrm{H}, \mathrm{H}-3^{\prime \prime}\right) .{ }^{13} \mathrm{C}$ NMR $\left(100 \mathrm{MHz}, \mathrm{CDCl}_{3}\right) \delta_{\mathrm{C}} 177.6(\mathrm{C}-4), 163.9(\mathrm{C}-2), 160.9$ (C-5), $160.4\left(\mathrm{C}-4^{\prime}\right), 159.8$ (C-9), 159.8 (C-7), $127.5\left(\mathrm{C}-2^{\prime}\right.$ and C-6' $), 124.7\left(\mathrm{C}-1^{\prime}\right), 115.2\left(\mathrm{C}-3^{\prime}\right.$ and $\left.\mathrm{C}-5^{\prime}\right), 109.2(\mathrm{C}-10), 107.9(\mathrm{C}-3), 96.1(\mathrm{C}-8), 92.8(\mathrm{C}-6), 77.9\left(\mathrm{C}-2^{\prime \prime}\right), 76.1\left(\mathrm{C}-3^{\prime \prime}\right), 56.4\left(\mathrm{C}-1^{\prime \prime}\right)$, $55.9\left(\mathrm{OCH}_{3}\right), 55.7\left(\mathrm{OCH}_{3}\right)$. HRESIMS $m / z 337.0495[\mathrm{M}+\mathrm{H}]^{+}\left(\operatorname{calcd} \mathrm{C}_{20} \mathrm{H}_{16} \mathrm{O}_{5}\right.$ 336.0998). 
Synthesis of 7-Methoxy, 4'-Propargyloxy-5-Hydroxyflavone (4c)

IUPAC.: 5-Hydroxy-7-methoxy-2-(4-(prop-2-yn-1-yloxy)phenyl)-4H-chromen-4-one. This procedure is similar to that for the preparation of the final flavonoid 1c. The final flavonoid 4c was purified in a silica column with 7:3 Hex-EtOAc, 1:1 Hex-EtOAc, 100\% EtOAc, 20:1 EtOAc-MeOH, and 9:1 EtOAc-MeOH (14 mg, 28\%). ${ }^{1} \mathrm{H}$ NMR $(400 \mathrm{MHz}$, $\left.\mathrm{CDCl}_{3}\right) \delta_{\mathrm{H}} 12.79(\mathrm{~s}, \mathrm{C}-5-\mathrm{OH}), 7.88\left(\mathrm{~d}, J=8.9 \mathrm{~Hz}, 2 \mathrm{H}, \mathrm{H}-2^{\prime}\right.$ and $\left.\mathrm{H}-6^{\prime}\right), 7.12(\mathrm{~d}, J=8.9 \mathrm{~Hz}, 2 \mathrm{H}$, H- $3^{\prime}$ and $\left.\mathrm{H}-5^{\prime}\right), 6.60(\mathrm{~s}, 1 \mathrm{H}, \mathrm{H}-3), 6.50(\mathrm{~d}, J=2.2 \mathrm{~Hz}, 1 \mathrm{H}, \mathrm{H}-6), 6.39(\mathrm{~d}, J=2.2 \mathrm{~Hz}, 1 \mathrm{H}, \mathrm{H}-8)$, $4.80\left(\mathrm{~d}, J=2.3 \mathrm{~Hz}, 2 \mathrm{H}, \mathrm{H}_{2}-1^{\prime \prime}\right), 3.90\left(\mathrm{~s}, 3 \mathrm{H}, \mathrm{OCH}_{3}\right), 2.59\left(\mathrm{t}, J=2.3 \mathrm{~Hz}, 1 \mathrm{H}, \mathrm{H}-3^{\prime \prime}\right) .{ }^{13} \mathrm{C} \mathrm{NMR}$ $\left(100 \mathrm{MHz}, \mathrm{CDCl}_{3}\right) \delta_{\mathrm{C}} 182.4$ (C-4), 165.5 (C-7), 163.8 (C-2), 162.2 (C-4'), 160.4 (C-5), 157.7 (C-9), $128.0\left(\mathrm{C}-2^{\prime}\right.$ and $\left.\mathrm{C}-6^{\prime}\right), 124.4\left(\mathrm{C}-1^{\prime}\right), 115.4\left(\mathrm{C}-3^{\prime}\right.$ and $\left.\mathrm{C}-5^{\prime}\right), 105.6(\mathrm{C}-10), 104.6(\mathrm{C}-3), 98.1$ (C-8), 92.6 (C-6), $77.7\left(\mathrm{C}-2^{\prime \prime}\right), 76.2\left(\mathrm{C}-3^{\prime \prime}\right), 55.9\left(\mathrm{C}-1^{\prime \prime}\right), 55.8\left(\mathrm{OCH}_{3}\right)$. HRESIMS $m / z 323.0767$ $[\mathrm{M}+\mathrm{H}]^{+}\left(\right.$calcd $\left.\mathrm{C}_{19} \mathrm{H}_{14} \mathrm{O}_{5} 322.0841\right)$.

2.2.2. Procedure for Preparation of Compounds 5

Synthesis of 4-(Cyclopropyl Methoxy)Benzaldehyde (Compound IV)

IUPAC.: 4-(Cyclopropylmethoxy)benzaldehyde. (Bromomethyl)cyclopropane (400 mg, $2.96 \mathrm{mmol}$ ) was added to 4-hydroxy benzaldehyde $(724 \mathrm{mg}, 5.92 \mathrm{mmol})$ and was dissolved in $15 \mathrm{~mL}$ of acetone and potassium carbonate $(1.6 \mathrm{~g}, 11.9 \mathrm{mmol})$. The mixture was then refluxed for $36 \mathrm{~h}$, then diluted with EtOAc and washed with water. This compound IV was purified in a silica column using 95:5 Hex-EtOAc (380 mg, 73\%). ${ }^{1} \mathrm{H}$ NMR $(400 \mathrm{MHz}$, $\left.\mathrm{CDCl}_{3}\right) \delta_{\mathrm{H}} 9.82(\mathrm{~s}, 1 \mathrm{H}, \mathrm{CHO}), 7.76(\mathrm{~d}, J=8.8 \mathrm{~Hz}, 2 \mathrm{H}, \mathrm{H}-2$ and $\mathrm{H}-6), 6.94(\mathrm{~d}, J=8.8 \mathrm{~Hz}, 2 \mathrm{H}$, $\mathrm{H}-3$ and $\mathrm{H}-5), 3.84\left(\mathrm{dd}, J=8.1,10.9 \mathrm{~Hz}, 2 \mathrm{H}, \mathrm{H}_{2}-\mathrm{1}^{\prime}\right), 1.27-1.21\left(\mathrm{~m}, 1 \mathrm{H}, \mathrm{H}-2^{\prime}\right), 0.64-0.61(\mathrm{~m}$, $2 \mathrm{H}, \mathrm{H}-3^{\prime} \mathrm{a}$ and $\left.\mathrm{H}-4^{\prime} \mathrm{a}\right), 0.34-0.32\left(\mathrm{~m}, 2 \mathrm{H}, \mathrm{H}-3^{\prime} \mathrm{b}\right.$ and $\left.\mathrm{H}-4^{\prime} \mathrm{b}\right) .{ }^{13} \mathrm{C}$ NMR $\left(100 \mathrm{MHz}, \mathrm{CDCl}_{3}\right) \delta_{\mathrm{C}}$ 190.7 (CHO), 164.0 (C-4), 131.9 (C-2 and C-6), 129.8 (C-1), 114.8 (C-3 and C-5), 73.0 (C-1'), $10.0\left(\mathrm{C}-2^{\prime}\right), 3.2\left(\mathrm{C}-3^{\prime}\right.$ and $\left.\mathrm{C}-4^{\prime}\right)$.

Synthesis of (E) 4-(Cyclopropyl Methoxy)-4' $6^{\prime}$-Dimethoxy-2'-Hydroxychalcone (5a)

IUPAC.: (E)-3-(4-(Cyclopropylmethoxy)phenyl)-1-(2-hydroxy-4,6-dimethoxyphenyl) prop-2-en-1-one. This procedure is similar to that for the preparation of the chalcone 1a except for the use of 4-(Cyclopropylmethoxy)benzaldehyde (compound IV) (270 mg, $1.53 \mathrm{mmol})$. The chalcone $5 \mathbf{a}$ was purified in a silica column with $4: 1 \mathrm{CH}_{2} \mathrm{Cl}_{2}-\mathrm{Hex}, 100 \%$ $\mathrm{CH}_{2} \mathrm{Cl}_{2}, 20: 1 \mathrm{CH}_{2} \mathrm{Cl}_{2}-\mathrm{MeOH}$, and 9:1 $\mathrm{CH}_{2} \mathrm{Cl}_{2}-\mathrm{MeOH}(287 \mathrm{mg}, 53 \%) .{ }^{1} \mathrm{H} \mathrm{NMR}(400 \mathrm{MHz}$, $\left.\mathrm{CDCl}_{3}\right) \delta_{\mathrm{H}} 14.42\left(\mathrm{~s}, \mathrm{C}-2^{\prime}-\mathrm{OH}\right), 7.84(\mathrm{~s}, \mathrm{br}, 2 \mathrm{H}, \mathrm{H}-\alpha$ and $\mathrm{H}-\beta), 7.55(\mathrm{~d}, J=8.7 \mathrm{~Hz}, 2 \mathrm{H}, \mathrm{H}-2$ and H-6), $6.93\left(\mathrm{~d}, J=8.7 \mathrm{~Hz}, 2 \mathrm{H}, \mathrm{H}-3\right.$ and H-5), $6.11\left(\mathrm{~d}, J=2.3 \mathrm{~Hz}, 1 \mathrm{H}, \mathrm{H}-3^{\prime}\right), 5.97(\mathrm{~d}, J=2.3 \mathrm{~Hz}$, $\left.1 \mathrm{H}, \mathrm{H}-5^{\prime}\right), 3.86\left(\mathrm{~s}, 2 \mathrm{H}, \mathrm{H}_{2}-1^{\prime \prime}\right), 3.92\left(\mathrm{~s}, 3 \mathrm{H}, \mathrm{OCH}_{3}\right), 3.84\left(\mathrm{~s}, 3 \mathrm{H}, \mathrm{OCH}_{3}\right), 1.31-1.27(\mathrm{~m}, 1 \mathrm{H}$, H-2"), 0.67 (dd, J = 4.9, $12.9 \mathrm{~Hz}, 2 \mathrm{H}, \mathrm{H}-3 " \mathrm{a}$ and H-4"a), 0.38 (dd, $J=4.9,10.3 \mathrm{~Hz}, 2 \mathrm{H}, \mathrm{H}-3{ }^{\prime \prime} \mathrm{b}$ and $\mathrm{H}-4{ }^{\prime \prime}$ b). ${ }^{13} \mathrm{C}$ NMR $\left(100 \mathrm{MHz}, \mathrm{CDCl}_{3}\right) \delta_{\mathrm{C}} 192.6(\mathrm{C}=\mathrm{O}), 168.3\left(\mathrm{C}-2^{\prime}\right), 166.0\left(\mathrm{C}-4^{\prime}\right), 162.4$ $\left(C-6^{\prime}\right), 160.8(C-4), 142.5(C-\beta), 130.1$ (C-2 and C-6), $128.2(C-1), 125.0(C-\alpha), 114.9$ (C-3 and C-5), $106.3\left(\mathrm{C}-1^{\prime}\right), 93.8\left(\mathrm{C}-3^{\prime}\right), 91.2\left(\mathrm{C}-5^{\prime}\right), 72.9\left(\mathrm{C}-1^{\prime \prime}\right), 55.8\left(\mathrm{OCH}_{3}\right), 55.5\left(\mathrm{OCH}_{3}\right), 10.2\left(\mathrm{C}-2^{\prime \prime}\right)$, 3.2 (C-3" and C-4"). HRESIMS $m / z 355.0575[\mathrm{M}+\mathrm{H}]^{+}\left(\right.$calcd $\left.\mathrm{C}_{21} \mathrm{H}_{22} \mathrm{O}_{5} 354.1467\right)$.

Synthesis of 5,7-Dimethoxy-4'(Cyclopropyl Methoxy)Flavone (5b)

IUPAC.: 2-(4-(Cyclopropylmethoxy)phenyl)-5,7-dimethoxy-4H-chromen-4-one. This procedure is similar to that for the preparation of the intermediate flavonoid $1 \mathrm{~b}$. The intermediate flavonoid $\mathbf{5 b}$ was purified in a silica column using 1:1 Hex-EtOAc, 100\% EtOAc, 20:1 EtOAc-MeOH, 9:1 EtOAc-MeOH, and 1:1 EtOAc-MeOH $(120 \mathrm{mg}, 78 \%) .{ }^{1} \mathrm{H}$ $\operatorname{NMR}\left(400 \mathrm{MHz}, \mathrm{CDCl}_{3}\right) \delta_{\mathrm{H}} 7.78\left(\mathrm{~d}, J=9.0 \mathrm{~Hz}, 2 \mathrm{H}, \mathrm{H}-2^{\prime}\right.$ and $\left.\mathrm{H}-6^{\prime}\right), 6.97(\mathrm{~d}, J=9.0 \mathrm{~Hz}, 2 \mathrm{H}$, H-3 $3^{\prime}$ and H-5'), $6.56(\mathrm{~s}, 1 \mathrm{H}, \mathrm{H}-3), 6.53(\mathrm{~d}, J=2.3 \mathrm{~Hz}, 1 \mathrm{H}, \mathrm{H}-6), 6.34(\mathrm{~d}, J=2.3 \mathrm{~Hz}, 1 \mathrm{H}, \mathrm{H}-8)$, $3.93\left(\mathrm{~s}, 3 \mathrm{H}, \mathrm{OCH}_{3}\right), 3.89\left(\mathrm{~s}, 3 \mathrm{H}, \mathrm{OCH}_{3}\right), 3.85\left(\mathrm{~d}, J=6.9 \mathrm{~Hz}, 2 \mathrm{H}, \mathrm{H}_{2}-1^{\prime \prime}\right), 1.25(\mathrm{t}, J=7.2,1 \mathrm{H}$, H-2"), $0.66\left(\mathrm{dd}, J=4.8,12.9 \mathrm{~Hz}, 2 \mathrm{H}, \mathrm{H}-3\right.$ "a and H-4"a), 0.37 (dd, $J=4.8,10.6 \mathrm{~Hz}, 2 \mathrm{H}, \mathrm{H}-3{ }^{\prime \prime} \mathrm{b}$ and H-4"b). ${ }^{13} \mathrm{C}$ NMR (100 MHz, CDCl 3 ) $\delta_{\mathrm{C}} 177.6$ (C-4), 163.9 (C-2), 161.5 (C-5), 160.8 $\left(\mathrm{C}-4^{\prime}\right), 160.7(\mathrm{C}-9), 159.8(\mathrm{C}-7), 127.5\left(\mathrm{C}-2^{\prime}\right.$ and $\left.\mathrm{C}-6^{\prime}\right), 123.6\left(\mathrm{C}-1^{\prime}\right), 114.9\left(\mathrm{C}-3^{\prime}\right.$ and $\left.\mathrm{C}-5^{\prime}\right), 109.1$ (C-10), 107.5 (C-3), $96.0(\mathrm{C}-8), 92.8(\mathrm{C}-6), 72.9\left(\mathrm{C}-1^{\prime \prime}\right), 56.4\left(\mathrm{OCH}_{3}\right), 55.7\left(\mathrm{OCH}_{3}\right), 10.1\left(\mathrm{C}-2^{\prime \prime}\right)$, $3.2\left(\mathrm{C}-3^{\prime \prime}\right.$ and C-4"). HRESIMS $m / z 353.0805[\mathrm{M}+\mathrm{H}]^{+}\left(\right.$calcd $\left.\mathrm{C}_{21} \mathrm{H}_{20} \mathrm{O}_{5} 352.1311\right)$. 


\subsubsection{Procedure for Preparation of Compounds 6-8}

Synthesis of (E) 4-Bromo-4', 6'-Dimethoxy-2'-Hydroxychalcone (6a)

IUPAC.: (E)-3-(4-Bromophenyl)-1-(2-hydroxy-4,6-dimethoxyphenyl)prop-2-en-1-one. A mixture of equimolar amounts of $2^{\prime}$-hydroxy- $4^{\prime}, 6^{\prime}$-dimethoxyacetophenone $(300 \mathrm{mg}$, $1.53 \mathrm{mmol}$ ) and 4-bromobenzaldehyde $(285 \mathrm{mg}, 1.53 \mathrm{mmol})$ was taken in a RBF and $10 \mathrm{~mL}$ of $50 \% \mathrm{NaOH}$ in ethanol was added and left for $16 \mathrm{~h}$ at rt. The resulting yellow precipitate was then suction filtered and washed with hexanes and $\mathrm{CH}_{2} \mathrm{Cl}_{2}$. The brominated chalcone 6a was then purified in a silica column using $10 \%$ EtOAc and hexanes $(361 \mathrm{mg}, 65 \%) .{ }^{1} \mathrm{H}$ NMR $\left(400 \mathrm{MHz}, \mathrm{CDCl}_{3}\right) \delta_{\mathrm{H}} 14.23\left(\mathrm{~s}, \mathrm{C}-2^{\prime}-\mathrm{OH}\right), 7.89(\mathrm{~d}, J=15.6 \mathrm{~Hz}, 1 \mathrm{H}, \mathrm{H}-\beta), 7.71(\mathrm{~d}$, $J=15.6 \mathrm{~Hz}, 1 \mathrm{H}, \mathrm{H}-\alpha), 7.55(\mathrm{~d}, J=8.4 \mathrm{~Hz}, 2 \mathrm{H}, \mathrm{H}-2$ and $\mathrm{H}-6), 7.47(\mathrm{~d}, J=8.4 \mathrm{~Hz}, 2 \mathrm{H}, \mathrm{H}-3$ and $\mathrm{H}-5), 6.13\left(\mathrm{~d}, J=2.2 \mathrm{~Hz}, 1 \mathrm{H}, \mathrm{H}-3^{\prime}\right), 5.98\left(\mathrm{~d}, J=2.2 \mathrm{~Hz}, 1 \mathrm{H}, \mathrm{H}-5^{\prime}\right), 3.93\left(\mathrm{~s}, 3 \mathrm{H}, \mathrm{OCH}_{3}\right)$, $3.86\left(\mathrm{~s}, 3 \mathrm{H}, \mathrm{OCH}_{3}\right) .{ }^{13} \mathrm{C}$ NMR $\left(100 \mathrm{MHz}, \mathrm{CDCl}_{3}\right) \delta_{\mathrm{C}} 192.3(\mathrm{C}=\mathrm{O}), 168.4\left(\mathrm{C}-4^{\prime}\right), 166.4\left(\mathrm{C}-6^{\prime}\right)$, $162.5\left(C-2^{\prime}\right), 140.8(C-\beta), 134.5(C-1), 132.1$ (C-3 and C-5), 129.7 (C-2 and C-6), $128.1(C-\alpha)$, 124.2 (C-4), $106.3\left(\mathrm{C}-1^{\prime}\right), 93.8\left(\mathrm{C}-3^{\prime}\right), 91.3\left(\mathrm{C}-5^{\prime}\right), 55.9\left(\mathrm{OCH}_{3}\right), 55.6\left(\mathrm{OCH}_{3}\right)$. HRESIMS $\mathrm{m} / z$ $363.1418[\mathrm{M}+\mathrm{H}]^{+}$(calcd $\mathrm{C}_{17} \mathrm{H}_{15} \mathrm{BrO}_{4}$ 362.0154).

Synthesis of 5,7-Dimethoxy-4'-Bromoflavone (6b)

IUPAC.: 2-(4-Bromophenyl)-5,7-dimethoxy-4H-chromen-4-one. The brominated chalcone (6a) $(200 \mathrm{mg}, 0.551 \mathrm{mmol})$ was treated with $3-4 \mathrm{~mol} \%$ of iodine crystals with a minimal amount of DMSO at $140{ }^{\circ} \mathrm{C}$ for $4-6 \mathrm{~h}$. The resulting white precipitate was extracted with $\mathrm{CH}_{2} \mathrm{Cl}_{2}$ and was removed by filtration. The filtrate was transferred into a separatory funnel, where the layers were separated as aqueous and organic. The organic layer was washed with $\mathrm{Na}_{2} \mathrm{~S}_{2} \mathrm{O}_{3}$, dried with $\mathrm{Na}_{2} \mathrm{SO}_{4}$, and concentrated. The intermediate flavonoid $\mathbf{6} \mathbf{b}$ was purified in a silica column with 1:1 Hex-EtOAc, 3:2 EtOAc-Hex, 4:1 EtOAc-Hex, and 9:1 EtOAc-Hex $(134 \mathrm{mg}, 67 \%) .{ }^{1} \mathrm{H}$ NMR $\left(400 \mathrm{MHz}, \mathrm{CDCl}_{3}\right) \delta_{\mathrm{H}} 7.72\left(\mathrm{~d}, J=8.7 \mathrm{~Hz}, 2 \mathrm{H}, \mathrm{H}-3^{\prime}\right.$ and $\left.\mathrm{H}-5^{\prime}\right), 7.62\left(\mathrm{~d}, J=8.7 \mathrm{~Hz}, 2 \mathrm{H}, \mathrm{H}-2^{\prime}\right.$ and $\left.\mathrm{H}-6^{\prime}\right), 6.64(\mathrm{~s}, 1 \mathrm{H}, \mathrm{H}-3), 6.55(\mathrm{~d}, J=2.3 \mathrm{~Hz}, 1 \mathrm{H}, \mathrm{H}-6)$, $6.37(\mathrm{~d}, J=2.3 \mathrm{~Hz}, 1 \mathrm{H}, \mathrm{H}-8), 3.95\left(\mathrm{~s}, 3 \mathrm{H}, \mathrm{OCH}_{3}\right), 3.91\left(\mathrm{~s}, 3 \mathrm{H}, \mathrm{OCH}_{3}\right) .{ }^{13} \mathrm{C} \mathrm{NMR}(100 \mathrm{MHz}$, $\left.\mathrm{CDCl}_{3}\right) \delta_{\mathrm{C}} 177.3(\mathrm{C}-4), 164.2(\mathrm{C}-2), 160.9$ (C-5), 159.8 (C-9), $159.5(\mathrm{C}-7), 132.2\left(\mathrm{C}-3^{\prime}\right.$ and C-5'), 130.4 (C-1'), 127.3 (C-2' and C-6'), $125.8\left(\mathrm{C}-4^{\prime}\right), 109.2$ (C-10 and C-3), 96.3 (C-8), 92.8 (C-6), $56.4\left(\mathrm{OCH}_{3}\right), 55.8\left(\mathrm{OCH}_{3}\right)$. HRESIMS m/z $361.1324[\mathrm{M}+\mathrm{H}]^{+}\left(\right.$calcd $\mathrm{C}_{17} \mathrm{H}_{13} \mathrm{BrO}_{4}$ 359.9997).

Synthesis of 5,7-Dimethoxy-4'-Aminopropylflavone (6c)

IUPAC.: 5,7-Dimethoxy-2-(4-(propylamino)phenyl)-4H-chromen-4-one. Sodium tertbutoxide (17 mg, $0.18 \mathrm{mmol}$ ), tris(dibenzylideneacetone)dipalladium (11 mg, $0.012 \mathrm{mmol}$ ), and 1,1'-binaphthalene-2,2'-diylbis(diphenylphosphine) $(8 \mathrm{mg}, 0.012 \mathrm{mmol}$ ) were dissolved in $5 \mathrm{~mL}$ of toluene. To this, the brominated intermediate flavonoid $6 \mathbf{b}(50 \mathrm{mg}, 0.138 \mathrm{mmol})$ and propylamine $(11 \mathrm{mg}, 0.18 \mathrm{mmol})$ were added dropwise with stirring at $\mathrm{rt}$, and the mixture was refluxed at $80{ }^{\circ} \mathrm{C}$ for $48 \mathrm{~h}$. The nitrogenated intermediate flavonoid was purified in a silica column using 7:3 EtOAc-Hex, 9:1 EtOAc-Hex, 100\% EtOAc, and 9:1 EtOAc-MeOH $(24 \mathrm{mg}, 52 \%) .{ }^{1} \mathrm{H}$ NMR $\left(500 \mathrm{MHz}, \mathrm{CDCl}_{3}\right) \delta_{\mathrm{H}} 7.67\left(\mathrm{~d}, \mathrm{~J}=10.9 \mathrm{~Hz}, 2 \mathrm{H}, \mathrm{H}-2^{\prime}\right.$ and $\left.\mathrm{H}-6^{\prime}\right), 6.61\left(\mathrm{~d}, J=10.9 \mathrm{~Hz}, 2 \mathrm{H}, \mathrm{H}-3^{\prime}\right.$ and $\left.\mathrm{H}-5^{\prime}\right), 6.52(\mathrm{~d}, J=2.6 \mathrm{~Hz}, 1 \mathrm{H}, \mathrm{H}-6), 6.50(\mathrm{~s}, 1 \mathrm{H}$, $\mathrm{H}-3), 6.33(\mathrm{~d}, J=2.5 \mathrm{~Hz}, 1 \mathrm{H}, \mathrm{H}-8), 3.92\left(\mathrm{~s}, 3 \mathrm{H}, \mathrm{OCH}_{3}\right), 3.88\left(\mathrm{~s}, 3 \mathrm{H}, \mathrm{OCH}_{3}\right), 3.13(\mathrm{t}, J=9.0 \mathrm{~Hz}$, $\left.2 \mathrm{H}, \mathrm{H}_{2}-1^{\prime \prime}\right), 1.66\left(\mathrm{ddd}, J=9.2,18.2,9.0 \mathrm{~Hz}, 2 \mathrm{H}, \mathrm{H}_{2}-2^{\prime \prime}\right), 1.00\left(\mathrm{t}, J=9.2 \mathrm{~Hz}, 3 \mathrm{H}, \mathrm{CH}_{3}-3^{\prime \prime}\right) .{ }^{13} \mathrm{C}$ $\operatorname{NMR}\left(125 \mathrm{MHz}, \mathrm{CDCl}_{3}\right) \delta_{\mathrm{C}} 177.8$ (C-4), 163.6 (C-2), 161.6 (C-5), 160.7 (C-4'), 159.7 (C-9), $150.9(\mathrm{C}-7), 127.5\left(\mathrm{C}-2^{\prime}\right.$ and $\left.\mathrm{C}-6^{\prime}\right), 119.0\left(\mathrm{C}-1^{\prime}\right), 112.1\left(\mathrm{C}-3^{\prime}\right.$ and $\left.\mathrm{C}-5^{\prime}\right), 109.2(\mathrm{C}-10), 105.8$ (C-3), $95.8(\mathrm{C}-8), 92.8(\mathrm{C}-6), 56.3\left(\mathrm{OCH}_{3}\right), 55.7\left(\mathrm{OCH}_{3}\right), 45.2\left(\mathrm{C}-1^{\prime \prime}\right), 22.5\left(\mathrm{C}-2^{\prime \prime}\right), 11.5(\mathrm{C}-3 ")$. HRESIMS $m / z 340.2991[\mathrm{M}+\mathrm{H}]^{+}$(calcd $\mathrm{C}_{20} \mathrm{H}_{21} \mathrm{NO}_{4} 339.1471$ ).

Synthesis of 7-Methoxy-4'-Aminopropyl-5-Hydroxyflavone (6d)

IUPAC.: 5-Hydroxy-7-methoxy-2-(4-(propylamino)phenyl)-4H-chromen-4-one. The nitrogenated intermediate flavonoid $\mathbf{6 c}(15 \mathrm{mg}, 0.044 \mathrm{mmol})$ was treated with double the moles of $1 \mathrm{~N}$ boron tribromide ( $22 \mathrm{mg}, 0.088 \mathrm{mmol}$ ) in the presence of $\mathrm{CH}_{2} \mathrm{Cl}_{2}$ at $\mathrm{rt}$ for 1-3 $\mathrm{h}$. The reactant solution was diluted with $10: 1 \mathrm{CH}_{2} \mathrm{Cl}_{2}: \mathrm{MeOH}$ and then washed with brine and water. $\mathrm{Na}_{2} \mathrm{SO}_{4}$ was added to the solution and left overnight. The solution was 
then filtered into a RBF, dried, and concentrated. The final compound $\mathbf{6} \mathbf{d}$ was purified in a silica column using 1:1 Hex-EtOAc (11 mg, 77\%). ${ }^{1} \mathrm{H} \mathrm{NMR}\left(500 \mathrm{MHz}, \mathrm{CDCl}_{3}\right) \delta_{\mathrm{H}} 12.90(\mathrm{~s}$, C-5-OH), $7.65\left(\mathrm{~d}, J=8.8 \mathrm{~Hz}, 2 \mathrm{H}, \mathrm{H}-2^{\prime}\right.$ and $\left.\mathrm{H}-6^{\prime}\right), 6.58\left(\mathrm{~d}, J=8.7 \mathrm{~Hz}, 2 \mathrm{H}, \mathrm{H}-3^{\prime}\right.$ and $\left.\mathrm{H}-5^{\prime}\right), 6.43$ $(\mathrm{s}, 1 \mathrm{H}, \mathrm{H}-3), 6.39(\mathrm{~d}, J=2.2 \mathrm{~Hz}, 1 \mathrm{H}, \mathrm{H}-6), 6.27(\mathrm{~d}, J=2.2 \mathrm{~Hz}, 1 \mathrm{H}, \mathrm{H}-8), 3.80\left(\mathrm{~s}, 3 \mathrm{H}, \mathrm{OCH}_{3}\right)$, $3.10\left(\mathrm{t}, J=7.2 \mathrm{~Hz}, 2 \mathrm{H}, \mathrm{H}_{2}-1^{\prime \prime}\right), 1.62\left(\mathrm{ddd}, J=7.4,7.2,7.3 \mathrm{~Hz}, 2 \mathrm{H}, \mathrm{H}_{2}-2^{\prime \prime}\right), 0.96(\mathrm{t}, J=7.4 \mathrm{~Hz}$, $\left.3 \mathrm{H}, \mathrm{CH}_{3}-3^{\prime \prime}\right) .{ }^{13} \mathrm{C}$ NMR $\left(125 \mathrm{MHz}, \mathrm{CDCl}_{3}\right) \delta_{\mathrm{C}} 182.3$ (C-4), 165.2 (C-7), $164.4(\mathrm{C}-2), 162.1$ (C-5 and C-4' $\left.{ }^{\prime}\right), 157.6(\mathrm{C}-9), 128.0\left(\mathrm{C}-2^{\prime}\right.$ and $\left.\mathrm{C}-6^{\prime}\right), 127.5\left(\mathrm{C}-1^{\prime}\right), 114.0\left(\mathrm{C}-3^{\prime}\right.$ and $\left.\mathrm{C}-5^{\prime}\right), 105.4$ (C-10), 103.0 (C-3), 97.9 (C-8), 92.5 (C-6), $55.8\left(\mathrm{OCH}_{3}\right), 29.7$ (C-1"), 22.1 (C-2"), $11.5\left(\mathrm{C}-3^{\prime \prime}\right)$. HRESIMS $m / z 326.2691[\mathrm{M}+\mathrm{H}]^{+}$(calcd $\mathrm{C}_{19} \mathrm{H}_{19} \mathrm{NO}_{4} 325.1314$ ).

Synthesis of 5,7-Dimethoxy-4'-Aminoisopropylflavone (7c)

IUPAC.: 2-(4-(Isopropylamino)phenyl)-5,7-dimethoxy-4H-chromen-4-one. This procedure is similar to that for the preparation of the intermediate flavonoid $\mathbf{6 c}$ except for the use of isopropylamine $(11 \mathrm{mg}, 0.18 \mathrm{mmol})$. The intermediate flavonoid $7 \mathrm{c}$ was purified in a silica column using 9:1 EtOAc-Hex (37 mg, 79\%). ${ }^{1} \mathrm{H}$ NMR $\left(400 \mathrm{MHz}, \mathrm{CDCl}_{3}\right) 7.65(\mathrm{~d}$, $J=8.7 \mathrm{~Hz}, 2 \mathrm{H}, \mathrm{H}-2^{\prime}$ and $\left.\mathrm{H}-6^{\prime}\right), 6.58\left(\mathrm{~d}, J=8.7 \mathrm{~Hz}, 2 \mathrm{H}, \mathrm{H}-3^{\prime}\right.$ and $\left.\mathrm{H}-5^{\prime}\right), 6.50(\mathrm{~d}, J=2.2 \mathrm{~Hz}$, $1 \mathrm{H}, \mathrm{H}-6), 6.48(\mathrm{~s}, 1 \mathrm{H}, \mathrm{H}-3), 6.31$ (d, J = $2.2 \mathrm{~Hz}, 1 \mathrm{H}, \mathrm{H}-8), 3.90\left(\mathrm{~s}, 3 \mathrm{H}, \mathrm{OCH}_{3}\right), 3.86(\mathrm{~s}, 3 \mathrm{H}$, $\left.\mathrm{OCH}_{3}\right), 3.67$ (sept $\left.J=6.4 \mathrm{~Hz}, 1 \mathrm{H}, \mathrm{H}-1{ }^{\prime \prime}\right), 1.22\left(\mathrm{~d}, J=6.4 \mathrm{~Hz}, 6 \mathrm{H}, \mathrm{H}-2 "\right.$ and $\left.\mathrm{H}-3{ }^{\prime \prime}\right) .{ }^{13} \mathrm{C}$ NMR $\left(100 \mathrm{MHz}, \mathrm{CDCl}_{3}\right) \delta_{\mathrm{C}} 177.7$ (C-4), 163.6 (C-2), 161.5 (C-5), 160.7 (C-4'), 159.7 (C-9), 150.0 (C-7), 127.5 (C-2' and C-6'), $118.8\left(\mathrm{C}-1^{\prime}\right), 112.5\left(\mathrm{C}-3^{\prime}\right.$ and $\left.\mathrm{C}-5^{\prime}\right), 109.1$ (C-10), 105.7 (C-3), 95.8 (C-8), $92.8(\mathrm{C}-6), 56.3\left(\mathrm{OCH}_{3}\right), 55.6\left(\mathrm{OCH}_{3}\right), 43.9\left(\mathrm{C}-1^{\prime \prime}\right), 22.7\left(\mathrm{C}-2^{\prime \prime}\right.$ and $\left.\mathrm{C}-3 "\right)$. HRESIMS $m / z 340.3005[\mathrm{M}+\mathrm{H}]^{+}\left(\right.$calcd $\left.\mathrm{C}_{20} \mathrm{H}_{21} \mathrm{NO}_{4} 339.1471\right)$.

Synthesis of 7-Methoxy-4'-Aminoisopropyl-5-Hydroxyflavone (7d)

IUPAC.: 5-Hydroxy-2-(4-(Isopropylamino)phenyl)-7-methoxy-4H-chromen-4-one. This procedure is similar to that for the preparation of the final compound $\mathbf{6 d}$. The final compound $7 \mathrm{~d}$ was purified in a silica column with 9:1 Hex-EtOAc (16 mg, 83\%). ${ }^{1} \mathrm{H}$ NMR (500 MHz, $\left.\mathrm{CDCl}_{3}\right) 13.00(\mathrm{~s}, \mathrm{C}-5-\mathrm{OH}), 7.74\left(\mathrm{~d}, J=8.9 \mathrm{~Hz}, 2 \mathrm{H}, \mathrm{H}-2^{\prime}\right.$ and $\left.\mathrm{H}-6^{\prime}\right), 6.64\left(\mathrm{~d}, J=8.9 \mathrm{~Hz}, 2 \mathrm{H}, \mathrm{H}-3^{\prime}\right.$ and $\left.\mathrm{H}^{-} 5^{\prime}\right), 6.52(\mathrm{~s}, 1 \mathrm{H}, \mathrm{H}-3), 6.48(\mathrm{~d}, J=2.3 \mathrm{~Hz}, 1 \mathrm{H}, \mathrm{H}-6), 6.37(\mathrm{~d}, J=2.3 \mathrm{~Hz}, 1 \mathrm{H}, \mathrm{H}-8), 3.90$ $\left(\mathrm{s}, 3 \mathrm{H}, \mathrm{OCH}_{3}\right), 3.75\left(\mathrm{sept}, J=6.3 \mathrm{~Hz}, 1 \mathrm{H}, \mathrm{H}-1^{\prime \prime}\right), 1.29\left(\mathrm{~d}, J=6.3 \mathrm{~Hz}, 6 \mathrm{H}, \mathrm{CH}_{3}-2^{\prime \prime}\right.$ and $\left.\mathrm{CH}_{3}-3^{\prime \prime}\right)$. ${ }^{13} \mathrm{C}$ NMR $\left(125 \mathrm{MHz}, \mathrm{CDCl}_{3}\right) \delta_{\mathrm{C}} 182.4(\mathrm{C}-4), 165.1(\mathrm{C}-7), 164.9$ (C-2), 162.1 (C-4'), 157.6 (C-5), $150.5(\mathrm{C}-9), 128.1\left(\mathrm{C}-2^{\prime}\right.$ and $\left.\mathrm{C}-6^{\prime}\right), 118.6\left(\mathrm{C}-1^{\prime}\right), 112.6\left(\mathrm{C}-3^{\prime}\right.$ and $\left.\mathrm{C}-5^{\prime}\right), 105.5(\mathrm{C}-10), 102.4(\mathrm{C}-3)$, 97.8 (C-8), $92.5(\mathrm{C}-6), 55.7\left(\mathrm{OCH}_{3}\right), 44.1\left(\mathrm{C}-1^{\prime \prime}\right), 22.8$ (C-2" and C-3"). HRESIMS $m / z 326.2691$ $[\mathrm{M}+\mathrm{H}]^{+}$(calcd $\left.\mathrm{C}_{19} \mathrm{H}_{19} \mathrm{NO}_{4} 325.1314\right)$.

Synthesis of 5,7-Dimethoxy-4'-(Cyclopropyl Methylamino)Flavone (8c)

IUPAC.: 2-(4-((Cyclopropylmethyl)amino)phenyl)-5,7-dimethoxy-4H-chromen-4-one. This procedure is similar to that for the preparation of the intermediate flavonoid $\mathbf{6 c}$ except for the use of (aminomethyl)cyclopropane $(13 \mathrm{mg}, 0.18 \mathrm{mmol})$. The intermediate flavonoid $8 \mathrm{c}$ was purified in a silica column using 7:3 EtOAc-Hex, 100\% EtOAc, 10:1 EtOAc-MeOH, and $100 \% \mathrm{MeOH}(40 \mathrm{mg}, 83 \%) .{ }^{1} \mathrm{H}$ NMR $\left(500 \mathrm{MHz}, \mathrm{CDCl}_{3}\right) 7.66\left(\mathrm{~d}, J=8.5 \mathrm{~Hz}, 2 \mathrm{H}, \mathrm{H}-2^{\prime}\right.$ and $\left.\mathrm{H}-6^{\prime}\right), 6.66\left(\mathrm{~d}, J=8.7 \mathrm{~Hz}, 2 \mathrm{H}, \mathrm{H}-3^{\prime}\right.$ and $\left.\mathrm{H}-5^{\prime}\right), 6.56(\mathrm{~s}, 1 \mathrm{H}, \mathrm{H}-3), 6.41(\mathrm{~d}, J=2.2 \mathrm{~Hz}$, $1 \mathrm{H}, \mathrm{H}-6), 6.38(\mathrm{~d}, J=2.2 \mathrm{~Hz}, 1 \mathrm{H}, \mathrm{H}-8), 3.97\left(\mathrm{~s}, 3 \mathrm{H}, \mathrm{OCH}_{3}\right), 3.92\left(\mathrm{~s}, 3 \mathrm{H}, \mathrm{OCH}_{3}\right), 3.05(\mathrm{~d}$, $\left.J=6.9 \mathrm{~Hz}, 2 \mathrm{H}, \mathrm{H}_{2}-1^{\prime \prime}\right), 1.12\left(\mathrm{~m}, 1 \mathrm{H}, \mathrm{H}-2^{\prime \prime}\right), 0.61(\mathrm{dd}, J=6.0,13.6 \mathrm{~Hz}, 2 \mathrm{H}, \mathrm{H}-3$ "a and H-4"a), $0.30\left(\mathrm{dd}, J=5.5,10.5 \mathrm{~Hz}, 2 \mathrm{H}, \mathrm{H}-3{ }^{\prime \prime} \mathrm{b}\right.$ and $\left.\mathrm{H}-4{ }^{\prime \prime} \mathrm{b}\right) .{ }^{13} \mathrm{C} \mathrm{NMR}\left(125 \mathrm{MHz}, \mathrm{CDCl}_{3}\right) \delta_{\mathrm{C}} 177.8(\mathrm{C}-4)$, 163.7 (C-2), 161.5 (C-5), 160.8 (C-4'), 160.9 (C-9), 159.8 (C-7), 127.5 (C-2' and C-6' $\left.{ }^{\prime}\right), 119.3$ $\left(\mathrm{C}-1^{\prime}\right), 112.3\left(\mathrm{C}-3^{\prime}\right.$ and $\left.\mathrm{C}-5^{\prime}\right), 109.3(\mathrm{C}-10), 106.0(\mathrm{C}-3), 96.3(\mathrm{C}-8), 92.8(\mathrm{C}-6), 56.5\left(\mathrm{OCH}_{3}\right)$, $55.7\left(\mathrm{OCH}_{3}\right), 48.5\left(\mathrm{C}-1^{\prime \prime}\right), 10.7\left(\mathrm{C}-2^{\prime \prime}\right), 3.6\left(\mathrm{C}-3^{\prime \prime}\right.$ and C-4"). HRESIMS $m / z 352.2586[\mathrm{M}+\mathrm{H}]^{+}$ (calcd $\mathrm{C}_{21} \mathrm{H}_{21} \mathrm{NO}_{4}$ 351.1471).

Synthesis of 7-Methoxy-4'-(Cyclopropyl Methylamino)-5-Hydroxyflavone (8d)

2-(4-((Cyclopropylmethyl)amino)phenyl)-5-hydroxy-7-methoxy-4H-chromen-4-one. This procedure is similar to that for the preparation of the final compound $\mathbf{6 d}$. The final compound 8d was purified in a sephadex column with 1:1 Hex-EtOAC (2 mg, 7\%). ${ }^{1} \mathrm{H}$ NMR $(500 \mathrm{MHz}$, 
$\left.\mathrm{CDCl}_{3}\right) 13.00(\mathrm{~s}, \mathrm{C}-5-\mathrm{OH}), 7.75\left(\mathrm{~d}, J=8.8 \mathrm{~Hz}, 2 \mathrm{H}, \mathrm{H}-2^{\prime}\right.$ and $\left.\mathrm{H}-6^{\prime}\right), 6.67\left(\mathrm{~d}, J=8.8 \mathrm{~Hz}, 2 \mathrm{H}, \mathrm{H}-3^{\prime}\right.$ and $\left.\mathrm{H}^{-5} 5^{\prime}\right), 6.53(\mathrm{~s}, 1 \mathrm{H}, \mathrm{H}-3), 6.48(\mathrm{~d}, J=2.1 \mathrm{~Hz}, 1 \mathrm{H}, \mathrm{H}-6), 6.37(\mathrm{~d}, J=2.1 \mathrm{~Hz}, 1 \mathrm{H}, \mathrm{H}-8), 3.90$ $\left(\mathrm{s}, 3 \mathrm{H}, \mathrm{OCH}_{3}\right), 3.07$ (d, J = 6.9 Hz, 2H, H2-1"), 1.14 (m, 1H, H-2"), 0.63 (dd, J = 5.9, $13.0 \mathrm{~Hz}$, 2H, H-3" a and H-4"a), 0.31 (dd, $J=4.9,9.9 \mathrm{~Hz}, 2 \mathrm{H}, \mathrm{H}-3{ }^{\prime \prime} \mathrm{b}$ and H-4"b). ${ }^{13} \mathrm{C}$ NMR $(125 \mathrm{MHz}$, $\left.\mathrm{CDCl}_{3}\right) \delta_{\mathrm{C}} 182.4(\mathrm{C}-4), 165.1(\mathrm{C}-7), 164.9(\mathrm{C}-2), 162.1\left(\mathrm{C}-4^{\prime}\right), 157.6$ (C-5), 151.3 (C-9), 128.1 (C-2' and $\left.\mathrm{C}-6^{\prime}\right), 118.9\left(\mathrm{C}-1^{\prime}\right), 112.3\left(\mathrm{C}-3^{\prime}\right.$ and $\left.\mathrm{C}-5^{\prime}\right), 105.5(\mathrm{C}-10), 102.5(\mathrm{C}-3), 97.8(\mathrm{C}-8), 92.5(\mathrm{C}-6)$, $55.7\left(\mathrm{OCH}_{3}\right), 48.4\left(\mathrm{C}-1^{\prime \prime}\right), 10.7\left(\mathrm{C}-2^{\prime \prime}\right), 3.6\left(\mathrm{C}-3^{\prime \prime}\right.$ and $\left.\mathrm{C}-4^{\prime \prime}\right)$. HRESIMS $m / z 338.2880[\mathrm{M}+\mathrm{H}]^{+}$ (calcd $\mathrm{C}_{20} \mathrm{H}_{19} \mathrm{NO}_{4}$ 337.1314).

\subsection{Evaluation of Pan Assay Interference Compounds (PAINS)}

All the designed MAO-B inhibitors were analyzed per the recently published editorial [14] using the False Positive Remover [15] and the ZINC Pattern Identifier [16]. All compounds passed the filter and were not reported as covalent inhibitors or potential PAINS by any of these algorithms.

\subsection{Monoamine Oxidase Inhibition Assay and Determination of $I C_{50}$ Values for Synthesized Compounds}

To investigate the inhibitory effect of the acacetin 7-O-methyl ether analogs on human recombinant $\mathrm{MAO}-\mathrm{A}$ and $\mathrm{MAO}-\mathrm{B}$, the kynuramine oxidation deamination assay was performed in 384-well plates as previously reported, with minor modifications [17]. A fixed single concentration of kynuramine substrate and varying concentrations of the test inhibitor were used to determine the $\mathrm{IC}_{50}$ values. The kynuramine concentrations for MAO-A and -B were $80 \mu \mathrm{M}$ and $50 \mu \mathrm{M}$, respectively. These concentrations of kynuramine were twice the apparent $\mathrm{K}_{\mathrm{M}}$ value for substrate binding [9,18]. The acacetin 7-O-methyl ether analogs were tested at the concentrations ranging from $0.001 \mu \mathrm{M}$ to $100 \mu \mathrm{M}$ for $\mathrm{MAO}-\mathrm{A}$ and -B inhibition assays. Enzymatic reactions were performed in $50 \mu \mathrm{L}$ of the assay mixture containing $0.1 \mathrm{M}$ potassium phosphate buffer, $\mathrm{pH}$ 7.4. The inhibitors and acacetin 7-O-methyl ether analogs were dissolved in DMSO, diluted in the buffer solution, and pre-incubated at $37{ }^{\circ} \mathrm{C}$ for $10 \mathrm{~min}$ (the final concentration of DMSO was $<1.0 \%$ ). Reactions were initiated by the addition of $12.50 \mu \mathrm{L}$ of MAO-A (to $5 \mu \mathrm{g} / \mathrm{mL}$ ) or -B (to $10 \mu \mathrm{g} / \mathrm{mL}$ ). The plate was incubated for $20 \mathrm{~min}$ at $37^{\circ} \mathrm{C}$, and the enzymatic reaction was terminated by the addition of $18.8 \mu \mathrm{L}$ of $2 \mathrm{~N} \mathrm{NaOH}$. Formation of the enzyme product, 4-hydroxyquinoline, was measured fluorometrically using a SpectraMax M5 fluorescence plate reader (Molecular Devices, Sunnyvale, CA, USA) with excitation (320 nm) and emission (380 nm) wavelengths and the Soft Max Pro program. The inhibition effects of enzyme activity were calculated as percent of product formation compared to the corresponding control (enzyme-substrate reaction) without inhibitors. Controls included the assays where the enzyme or the substrate was added after terminating the reaction to determine the interference with the fluorescence measurements. The $\mathrm{IC}_{50}$ values for MAO-A and -B inhibition were calculated from the concentration-dependent inhibition curves using $\mathrm{XLFit}^{\circledR}$ software.

The enzyme assay was performed at a fixed concentration of the substrate kynuramine (80 $\mu \mathrm{M}$ for MAO-A and $50 \mu \mathrm{M}$ for MAO-B) and varying concentrations of the inhibitor/test analogs $(0.01 \mu \mathrm{M}$ to $100 \mu \mathrm{M})$ for MAO-A and $(0.01 \mu \mathrm{M}$ to $100 \mu \mathrm{M})$ for MAO-B. The doseresponse curves were generated using Microsoft ${ }^{\circledR}$ Excel and the $\mathrm{IC}_{50}$ values were calculated using XLfit software [9].

\subsection{Enzyme Kinetics, Mechanism Studies, Analysis of Reversibility, and Binding Assays of Acacetin 7-O-Methyl Ether Analogs}

For determination of the binding affinity of the inhibitor $(K i)$ with MAO-B, the enzyme assays were carried out at different concentrations of kynuramine substrate $(1.90 \mu \mathrm{M}$ to $500 \mu \mathrm{M})$ and varying concentrations of the test compound. Acacetin 7-O-methyl ether analogs: 1c, 2c, 3c, and 4c were tested at $0.015-0.500 \mu \mathrm{M}$ for MAO-B to determine the $K_{m}$ and $V_{\max }$ values of the enzymes in the presence of the inhibitor. The controls without inhibitor were also run simultaneously. Three sets of assays were performed at varying 
concentrations of the substrate for each experiment: one control without inhibitor and the others at two fixed concentrations of the inhibitor. The data were analyzed by double reciprocal Lineweaver-Burk plots to determine $K i$ (i.e., inhibition/binding affinity) values and the kinetic data, namely $K \mathrm{~m}, V \max$, and $K i$ values, were computed by SigmaPlot 12 [9].

Most of the inhibitors produce inhibition of the target enzyme activity through formation of an enzyme-inhibitor complex. Formation of the enzyme-inhibitor complex may be accelerated in the presence of a high concentration of the inhibitor. The reversibility/irreversibility of binding of acacetin 7-O-methyl ether analogs with MAO-B was determined from the formation of the complex by incubating the enzyme with a high concentration of the inhibitor followed by extensive equilibrium-dialysis of the enzymeinhibitor complex. Recovery of the catalytic activity of the enzyme was determined by assay of the enzyme activity before and after equilibrium-dialysis. MAO-B $(0.2 \mathrm{mg} / \mathrm{mL}$ protein) enzyme was incubated with each analog, namely acacetin $(0.5 \mu \mathrm{M}), 1 \mathrm{c}(1.5 \mu \mathrm{M})$, 2c $(1.5 \mu \mathrm{M}), 3 \mathrm{c}(1.5 \mu \mathrm{M}), 4 \mathrm{c}(1.5 \mu \mathrm{M})$, and deprenyl $(0.5 \mu \mathrm{M})$, in a total volume of $1 \mathrm{~mL}$ of potassium phosphate buffer $(100 \mathrm{mM}, \mathrm{pH} 7.4)$. After $20 \mathrm{~min}$ of incubation at $37^{\circ} \mathrm{C}$, the reaction was stopped by chilling the tubes in the ice bath. All the samples were dialyzed against potassium phosphate buffer $\left(25 \mathrm{mM}\right.$; pH 7.4) at $4{ }^{\circ} \mathrm{C}$ for $14-18 \mathrm{~h}$ (with three buffer changes). The control enzyme (without inhibitor) was also run simultaneously using the same procedure and the activity of the enzyme was determined before and after the dialysis.

To analyze if the nature of MAO-B binding to the inhibitor was time-dependent, the enzyme was pre-incubated for different time periods (0-15 $\mathrm{min}$ ) with the inhibitor concentrations, which exhibited approximately $70-80 \%$ inhibition. The inhibitor concentrations used to test time-dependent inhibition were acacetin $(0.080 \mu \mathrm{M}), 1 \mathrm{c}(0.100 \mu \mathrm{M}), 2 \mathrm{c}(0.300 \mu \mathrm{M})$, 3c $(0.300 \mu \mathrm{M}), 4 \mathrm{c}(0.400 \mu \mathrm{M})$, and deprenyl $(0.080 \mu \mathrm{M})$ with MAO-B $(12.5 \mu \mathrm{g} / \mathrm{mL})$. The controls, without inhibitors, were also run simultaneously. Activities of the enzyme were determined as described above, and the percentage of the remaining enzyme activity was plotted against the pre-incubation time to determine time-dependent inhibition.

\subsection{Molecular Modeling Studies}

The crystal structures of MAO-A (PDB ID: 2Z5Y with an atomic resolution of $2.17 \AA$ ) and MAO-B (PDB ID: 4A79 with an atomic resolution of $1.89 \AA$ ) were downloaded from the protein databank (www.rcsb.org, accessed on 12 January 2017). The protein structural files were prepared using the protein preparation wizard of Schrödinger suite [19]. Standard procedures were followed for protein preparation through assigning bond orders, adding hydrogens and removing original ones, creating zero-order bonds to metals, filling in the missing side chains, and deleting waters beyond $5 \AA$ from the ligand. The ionization states were generated at pH 7.4 using Epik [20-22]. The next step was sampling water orientations and checking for possible protonation and tautomerization states at $\mathrm{pH}$ 7.4. Water molecules that did not display at least two hydrogen bonds with no-water residues were deleted. Finally, the structure was relaxed to remove all atomic clashes using OPLS3 force field [23].

The receptor grid was generated using Glide [24-27]. The binding pocket was identified by the ligand coordinates. Because of the importance of the FAD cofactor in directing the right pose in the substrate binding pocket [28-30], it was kept during the construction of the docking grids. The dimensions of the docking grid of MAO-A are: a grid center of $-40.89 \times-26.66 \times-14.85$, an inner box of $10 \times 10 \times 10$, and an outer box of $22.59 \times 22.59 \times 22.59(\AA)$. The dimensions of the MAO-B grid are: a grid center of $14.02 \times 130.51 \times 25.58$, an inner box of $10 \times 10 \times 10$, and an outer box of $26.74 \times 26.74$ $\times 26.74(\AA)$. The soft docking protocol was followed by softening the potential of nonpolar parts of the receptor (i.e., decreasing the van der Waals radius of nonpolar atoms to accommodate ligands). Ligands were prepared for docking using LigPrep [31]. This step was performed for acacetin 7-O-methyl ether and for the designed compounds as well. Possible protonation and tautomerization states were generated at a $\mathrm{pH}$ of 7.4 and 
the specified chiralities were retained. The lowest energy conformer of each ligand was kept. OPLS force field was employed in the preparation step. Acacetin 7-O-methyl ether and the designed compounds were docked into the receptor grids of MAO-A/B. The soft docking protocol [32] was followed by using flexible ligand sampling and the soft receptor grid. Standard docking precision was used to generate the best five poses for acacetin 7-O-methyl ether and the best pose for the other compounds.

The two most diverse poses of acacetin 7-O-methyl ether were used for molecular dynamics simulations and mapping of the active site water molecules. Each complex was prepared and solvated in an orthorhombic box of the TIP4P water solvation model using Desmond system builder $[33,34]$. The net charge on the protein was neutralized by adding the appropriate number of sodium ions. MD simulations were conducted using OPLS3 force field. The FAD cofactor was included in the MD studies and it was prepared by OPLS3 force field and charges. The cofactor showed a state penalty of $0.65 \mathrm{kcal} / \mathrm{mol}$ and a hydrogen bond count of 16 at a negative charge of -2 . Desmond's minimization algorithm was used to relax the MD system for 2000 iterations. Desmond's algorithm involves a series of energy minimizations and short $\mathrm{MD}$ simulations to further relax the solvated protein before the MD production step, including two minimization steps and 4 short MD simulation steps for 12 ps, 12 ps, 24 ps, and 24 ps at $10 \mathrm{~K}, 10 \mathrm{~K}, 300 \mathrm{~K}$, and $300 \mathrm{~K}$, respectively, using the NPT ensemble. For the production step of the MD simulations, the NPT ensemble, the Nose-Hoover chain thermostat, and the MartynaTobias-Klein barostat [33,34] were used. The coordinates were saved at intervals of $25 \mathrm{ps,}$ ending with 8000 frames, and the MD simulations were sampled over $200 \mathrm{~ns}$. The active site water structure and thermodynamic stability were examined for the protein-ligand complexes using SZMAP [35-37]. Positive (unfavorable) and negative (favorable) free energy hydration sites of the protein-ligand complexes were identified by implementing the semi-continuous solvation model of SZMAP to map the surface of the protein-binding pocket.

\section{Results and Discussion}

\subsection{Comparison of Acacetin and Acacetin 7-O-Methyl Ether with Known Flavonoids}

The structural requirements of the flavonoid skeleton are provided in Figure 1 and a simple comparison of the $\mathrm{IC}_{50}$ values of the related flavonoids (Table 1) gave more insight into our computational approach.

Table 1. Comparison of the $\mathrm{IC}_{50}$ values of acacetin and acacetin 7-O-methyl ether with known flavonoids.

\begin{tabular}{|c|c|c|c|}
\hline Flavonoids & $\begin{array}{c}\text { MAO-A } \\
\left(\mathrm{IC}_{50}, \mu \mathrm{M}\right)\end{array}$ & $\begin{array}{c}\text { MAO-B } \\
\left(\mathrm{IC}_{50}, \mu \mathrm{M}\right) *\end{array}$ & $\begin{array}{c}\text { Selectivity Index } \\
\text { MAO-A/B }\end{array}$ \\
\hline Naringenin [38] & $955 \pm 129$ & $288 \pm 18$ & 3.32 \\
\hline Chrysin [39] & $0.25 \pm 0.04$ & $1.04 \pm 0.17$ & 0.24 \\
\hline Rhamnocitrin [40] & $0.051 \pm 0.001$ & $2.97 \pm 2.97$ & 0.02 \\
\hline $4^{\prime}$-O-Methyl kaempferol [38] & $1.350 \pm 0.198$ & $>100$ & 0.01 \\
\hline 3,4'-Di-O-methyl kaempferol [41] & $0.033 \pm 0.042$ & $9.667 \pm 2.39$ & 0.03 \\
\hline Quercetin [39] & $1.52 \pm 0.09$ & $28.39 \pm 5.41$ & 0.05 \\
\hline Isorhamnetin [42] & $6.42 \pm 7.69$ & $21.2 \pm 4.99$ & 0.30 \\
\hline Luteolin [43] & $8.57 \pm 0.47$ & $>100$ & 0.08 \\
\hline Vetulin [11] & $18.79 \pm 0.29$ & $0.44 \pm 0.01$ & 42.70 \\
\hline Diosmetin [42] & $5.74 \pm 0.57$ & $1.58 \pm 0.88$ & 3.63 \\
\hline Apigenin [44] & $0.64 \pm 0.11$ & $1.12 \pm 0.27$ & 0.30 \\
\hline Genkwanin [40] & $0.14 \pm 0.01$ & $0.35 \pm 0.03$ & 0.40 \\
\hline Acacetin [9] & $0.121 \pm 0.001$ & $0.049 \pm 0.0007$ & 4.28 \\
\hline Acacetin 7-O-methyl ether [11] & $>100$ & $0.198 \pm 0.001$ & $>505.05$ \\
\hline
\end{tabular}

* The $\mathrm{IC}_{50}$ values computed from the dose-response inhibition curves are mean \pm S.D. of triplicate observations. Luteolin data were obtained by chemiluminescent assays using a MAO-Glo kit. All other flavonoid $\mathrm{IC}_{50}$ data were obtained by spectrometric/fluorometric techniques similar to those followed here using kynuramine as a substrate and human recombinant MAO A/B (see Section 2.4), except for naringenin where a chromogenic solution was used and $\mathrm{MAO} \mathrm{A} / \mathrm{B}$ where a rat liver mitochondrial fraction was used. 


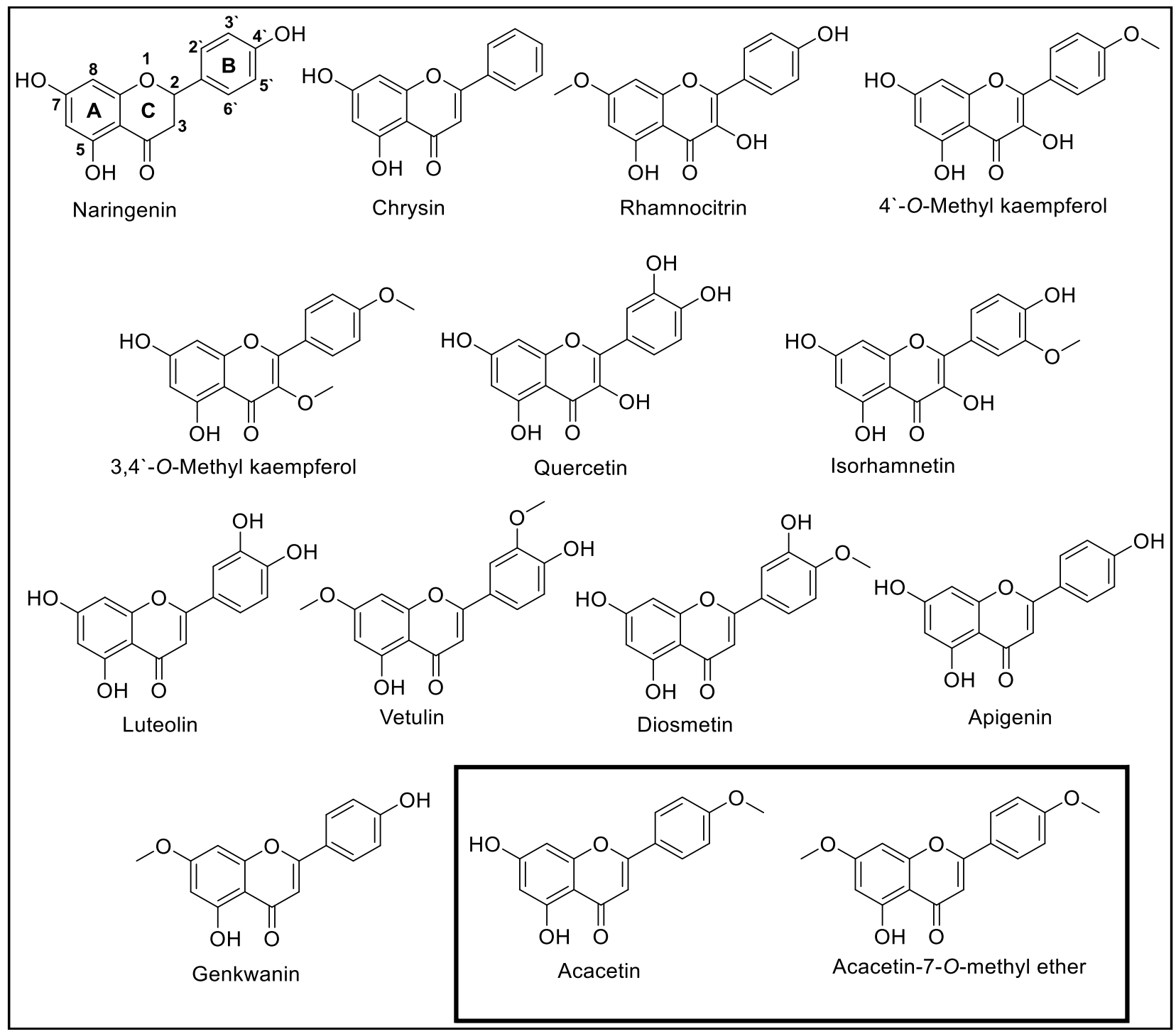

Figure 1. Comparison of acacetin and acacetin 7-O-methyl ether with known flavonoids.

The lack of a double bond between the C-2 and C-3 positions resulted in the depletion of MAO inhibition as seen in the flavanone naringenin [38]. The absence of substituents on ring B showed a slight preference for MAO-A in a manner similar to the flavone chrysin [39]. Monosubstitution on ring $B$ of the flavonol scaffold decreased the SI of MAO-A versus $\mathrm{MAO}-\mathrm{B}$, improving the activity towards MAO-A in a manner comparable to the flavonols rhamnocitrin [40], 4'-O-methyl kaempferol, and 3, 4'-O-methyl kaempferol [41], while disubstitution of ring $\mathrm{B}$ resulted in the loss of MAO-A activity as seen with the flavonols quercetin [39] and isorhamnetin [42]. Dioxygenation at positions C- $3^{\prime}$ and C-4 ${ }^{\prime}$ on ring $\mathrm{B}$ resulted in the loss of selectivity towards MAO-B in a manner similar to the flavone luteolin [43], while methoxylation of the same positions gained MAO-B selectivity in a manner similar to vetulin [11] and diosmetin [42], respectively. Monosubstitution of ring B on the flavone scaffold at C-4' resulted in no selectivity towards any MAO as seen with apigenin [44], genkwanin [40], and acacetin [9]. Methylation of the C-7 position increased selectivity towards MAO-B in a manner similar to acacetin-7-O-methyl ether [11]. Based on this SAR analysis, oxygenation at the $C-5$ and $C-7$ positions of ring $A$ is significant for $\mathrm{MAO}$ inhibition. Oxygenation of the $\mathrm{C}-3$ position resulted in MAO-A selectivity, while substitution on $\mathrm{C}-4^{\prime}$ resulted in MAO-B selectivity. 


\subsection{In Silico Optimization and Design}

3.2.1. Molecular Dynamics (MD) Simulations of the Binding Modes of Acacetin and Acacetin 7-O-Methyl Ether

Acacetin 7-O-methyl ether was recently discovered to be a selective MAO-B inhibitor with $0.198 \mu \mathrm{M}$ inhibition of MAO-B versus MAO-A $(>100 \mu \mathrm{M})$ [11]. The binding characteristics of acacetin 7-O-methyl ether were studied to understand the basis of target selectivity. Molecular constraints were imposed on the system during docking simulations based on our previous investigations [9]. The chemistry of the acacetin 7-O-methyl ether was mapped with the binding site environment using molecular dynamics (MD) simulations and thermodynamic calculations to better define the most abundant binding mode. The same analysis was carried out for acacetin (Figures S1-S73, see Supplementary Materials).

Acacetin 7-O-methyl ether demonstrated a very strong binding interaction with $\mathrm{MAO}$ $\mathrm{B}$ and a very weak binding to MAO-A. Figure 2 shows the binding of acacetin 7-O-methyl ether with and without constraints to MAO-A and -B. Acacetin 7-O-methyl ether was docked preferentially with a docking score of $-8.9 \mathrm{kcal} / \mathrm{mol}$ into MAO-B and a docking score of $-6.7 \mathrm{kcal} / \mathrm{mol}$ into MAO-A, without forcing the constraints. The benzopyranone was located between the aromatic cages (Tyr residues) in both cases, and the terminal phenyl group interacted with the aromatic gating amino acids (Phe208 for MAO-A, and Tyr326 for MAO-B). Keeping the water molecules close to the gating amino acids clashed with the phenyl group in the case of MAO-A, while it allowed two possible poses for MAO-B.

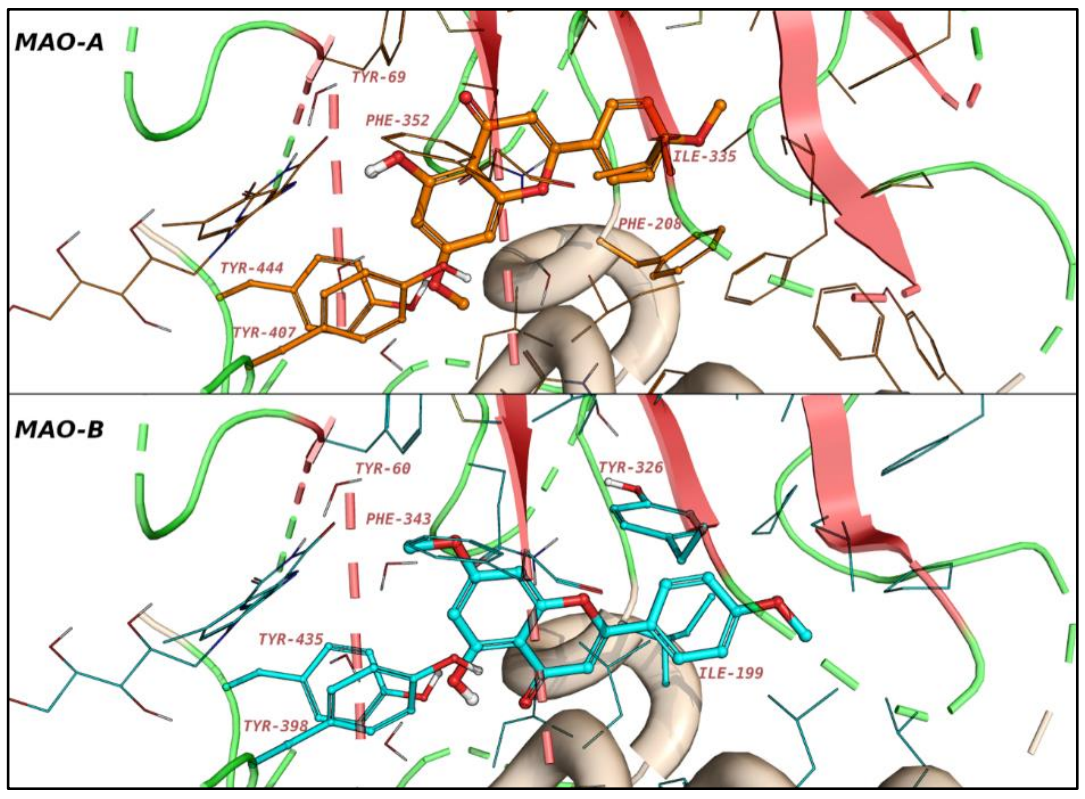

Figure 2. The predicted binding modes of acacetin ether in MAO-A and MAO-B. The gating amino acids (Ile335 and Phe208 of MAO-A, Ile199 and Tyr326 of MAO-B) and the aromatic cages (Tyr407 and Tyr444 of MAO-A, Tyr398 and Ty435 of MAO-B) are shown as sticks.

The two possible binding modes for acacetin 7-O-methyl ether in the case of MAO-B were visualized and are shown in Figure 3. The first pose of acacetin 7-O-methyl ether has benzopyranone facing the cofactor (referred to as pose 1, Figure 3A) and in the second pose, the methoxyphenyl group is facing the cofactor (referred to as pose 2, Figure 3B). Pose 1 has a better docking score compared with pose 2 . The average root mean square deviation (RMSD) of pose 1 was $3.2 \AA$ with respect to $1.6 \AA$ for the protein backbone over the course of the MD simulations. 


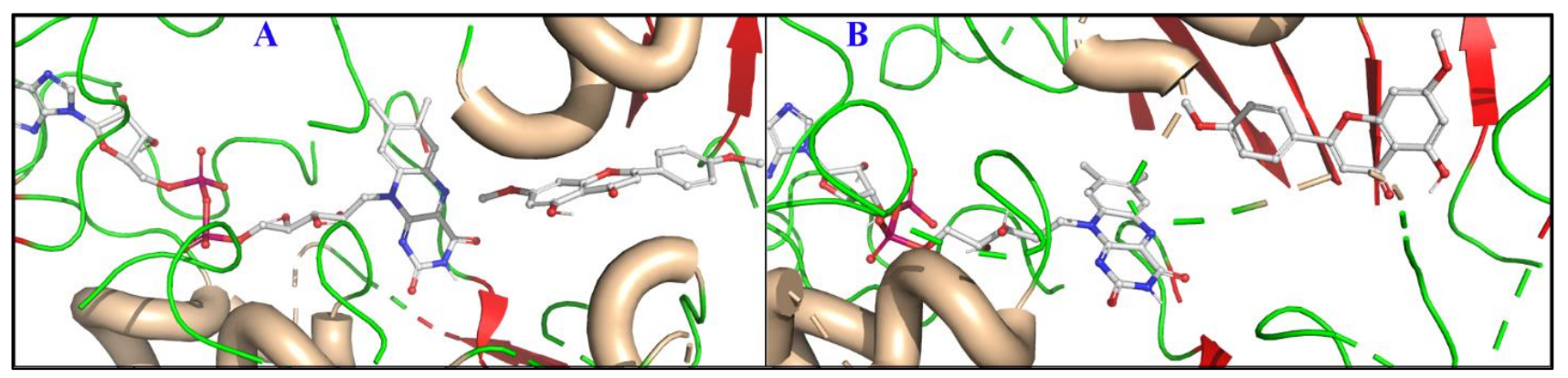

Figure 3. The two binding modes of acacetin 7-O-methyl ether. (A) Pose 1 with benzopyranone facing the FAD. (B) Pose 2 with the methoxyphenyl group facing the FAD. The protein is shown as a cartoon (helices are colored wheat, strands are colored red, and loops are colored green) and the ligands as sticks.

Pose 2 exhibited a RMSD value of $\sim 1.6 \AA$, while the RMSD of the protein backbone was $2.3 \AA$ A. Large local changes were observed along the protein chains between amino acids 99-102, particularly in the case of pose 2 (Figure S74). These local changes could be attributed to ligand binding (Figures 4 and S75) leading to high fluctuations in the RMSD values (Figure S74).

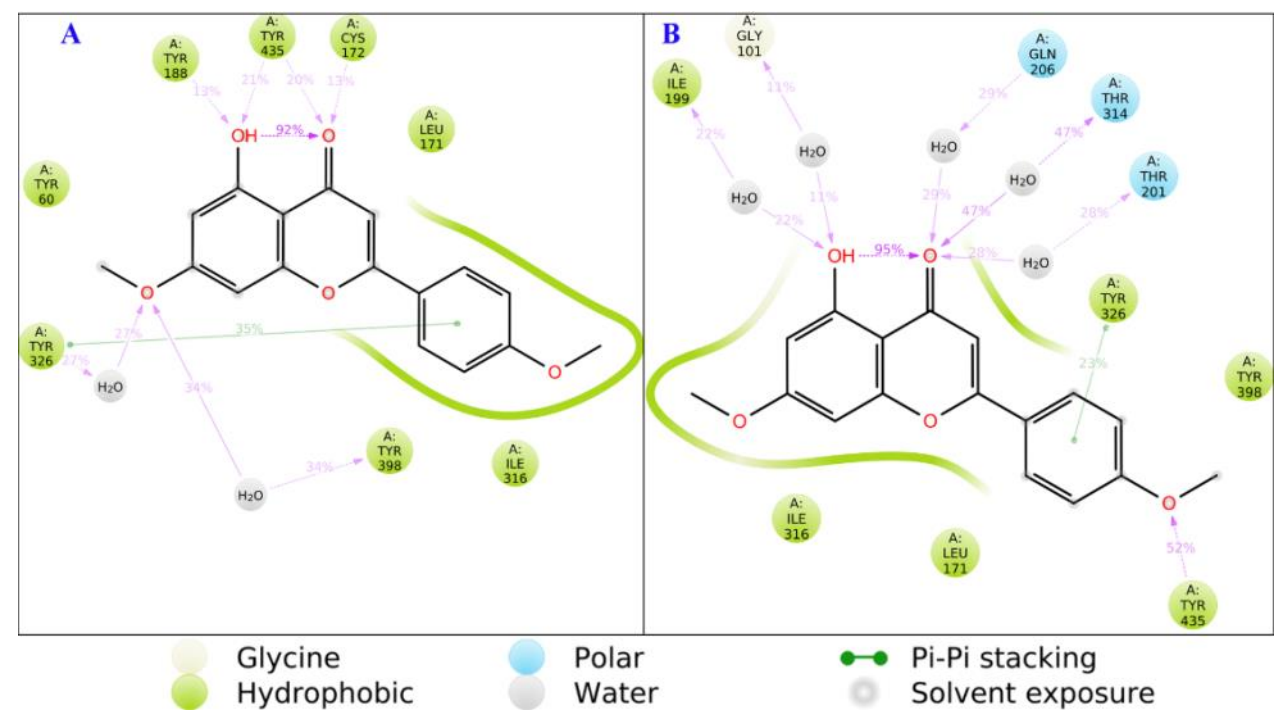

Figure 4. The 2D protein-ligand contacts for pose 1 (A) and pose 2 (B) for acacetin 7-O-methyl ether.

3.2.2. Active Site Hydration of MAO-B: MD Simulations, Thermodynamics, and Ligand Designs

There are 10 crystallographic water molecules in the binding pocket of MAO-B, which would have significant effects on ligand recognition and ligand design. The exact location of active site water molecules was confirmed by thermodynamic calculations to assess their contributions in ligand binding and target selectivity. Analysis of the MD simulations revealed that an average of three water molecules were fluctuating near the cofactor. In the case of pose 1, the ligand interacts with the hydrogen bond to Pro 102 through a water molecule for $\sim 5 \%$ of the MD simulation time. On the other hand, pose 2 showed hydrogen bonds through water molecules to Phe 99 (less than 5\%), Gly 101 (11\%), and Pro 102 ( 5\%). More hydrophobic contacts were observed for pose 1 , while more hydrogen bonds and water bridges were traced for pose 2 (Figure S75).

In conclusion, water molecules are more involved in the binding of pose 2 (Figures 4-6). Several other important protein-ligand contacts for both poses were sampled over the course of MD simulations, including hydrophobic contacts, $\pi-\pi$ stacking, hydrogen bond- 
ing, and interactions through water bridges with Leu 171, Leu 316, Tyr 326, Tyr 398, and Tyr 435 (Figure 4).

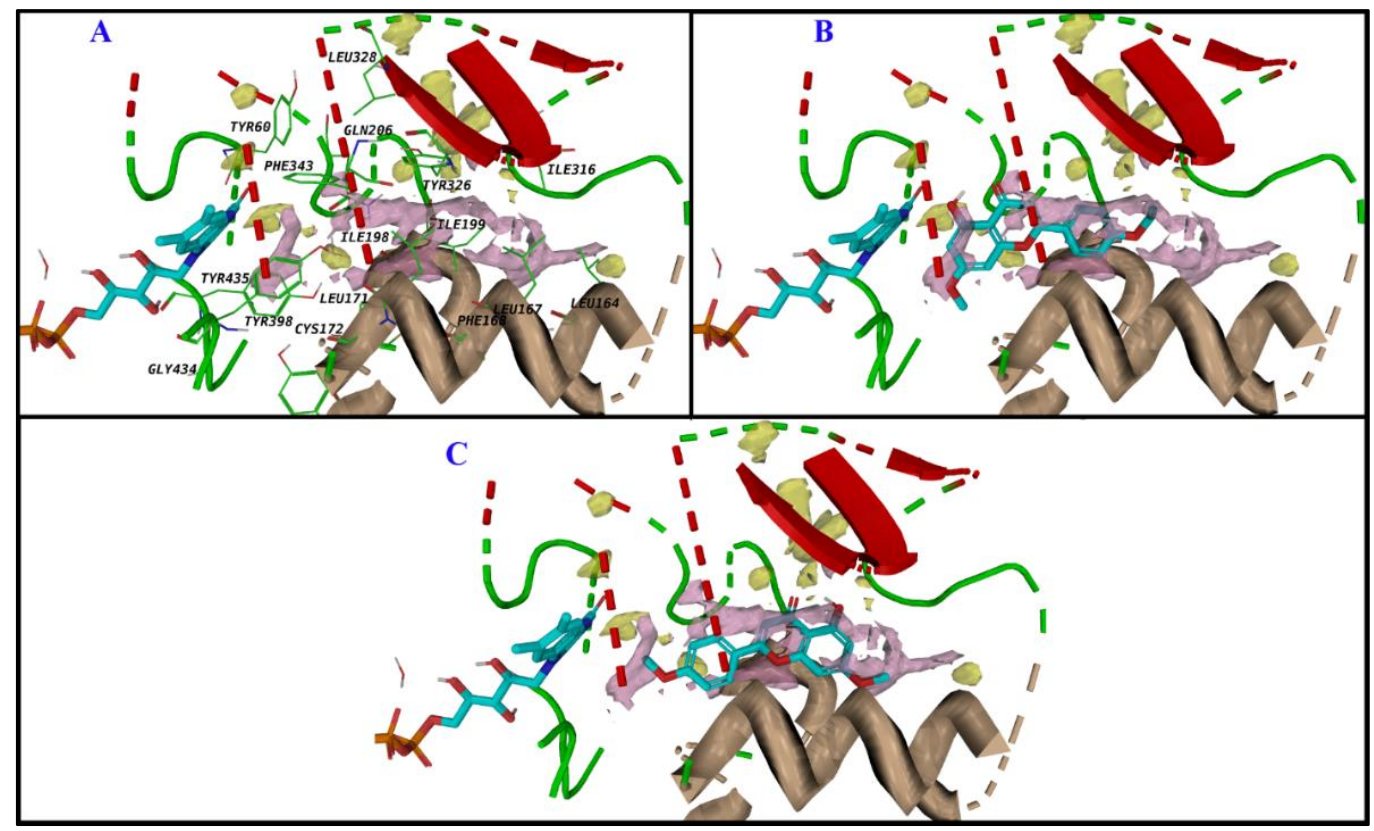

Figure 5. Water map of the MAO-B active site (A) and fitting of pose 1 (B) and pose 2 (C) with site hydration properties. Favorable regions for water molecules and polar groups are shown as yellow surfaces; hydrophobic regions are shown in purple.

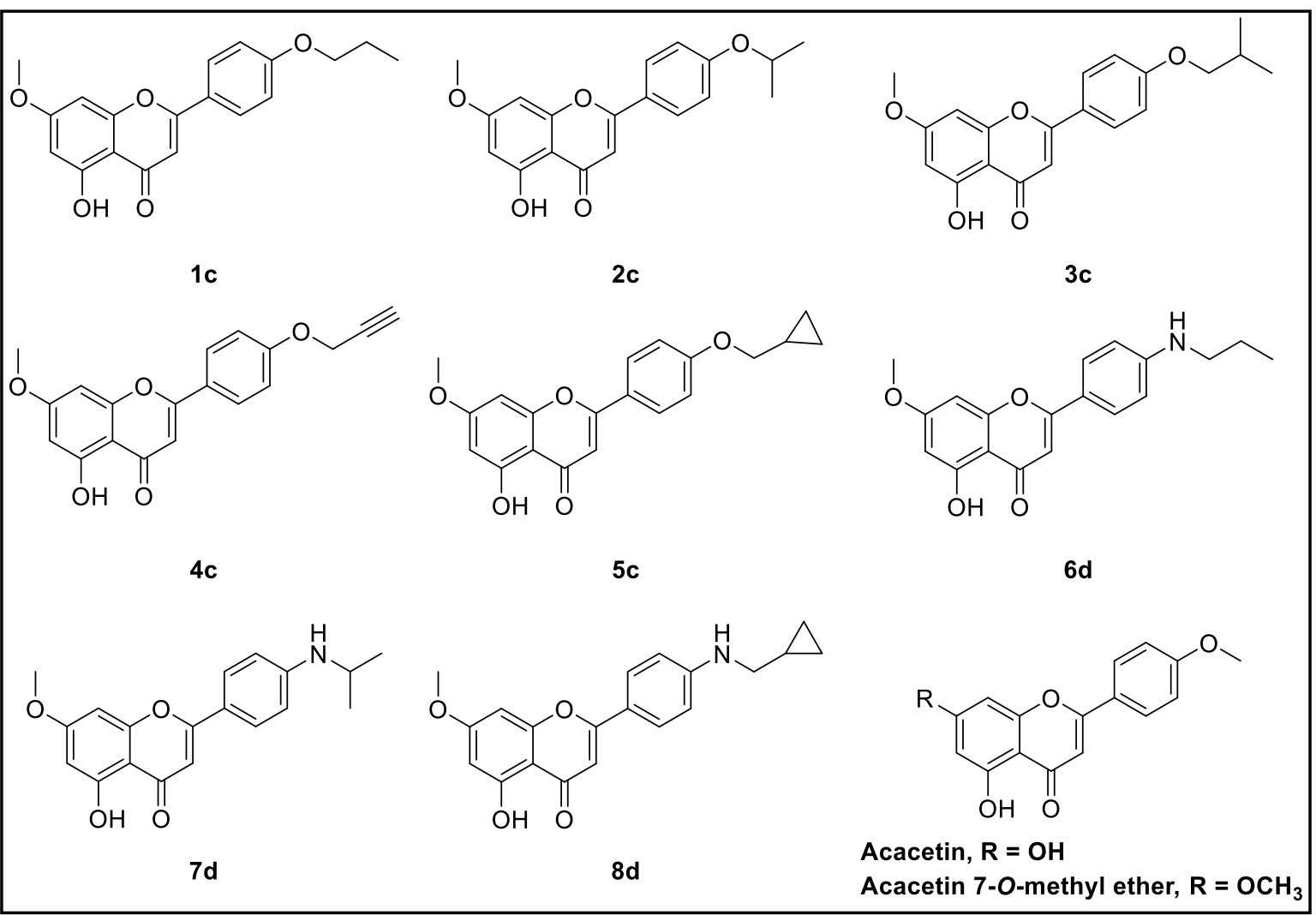

Figure 6. Designed acacetin 7-O-methyl ether analogs.

The active site water molecules (Figure 5A) were also investigated by water mapping calculations to compute their free energy and predict their effect on target selectivity. 
The binding pocket of MAO-B has a hydration shell near the cofactor (which is similar to what was found during the MD) that overlaps well with the hydroxyl group of the benzopyranone of pose 1 (Figure 5B). Therefore, to design high-affinity ligands, we should keep the hydroxyl group or modify the structure to have more polarity at the same position. A hydrophobic region (a positive free energy region) was noticed at the opposite site of FAD; and it covers the methoxyphenyl group of acacetin 7-O-methyl ether. To improve ligand binding, the polarity should be decreased at this position. The ligand chemistry of pose 2 did not fit well with the active site hydration map, while pose 1 showed a perfect match (Figure 5C).

Based on the interaction profile of acacetin 7-O-methyl ether as well as the thermodynamic properties of MAO-B's active site, eight analogs were virtually designed to have small ether and/or amine modifications at $\mathrm{C}-4^{\prime}$ of the acacetin 7-O-methyl ether scaffold (Figure 6) and docked into the active sites of MAO-A and -B using Glide (Table S1).

The designed compounds were evaluated for their absorption, distribution, metabolism, and excretion (ADME) properties. They did not show any violation of the rules of five or three; they have a good balance of lipophilicity/hydrophilicity, and are expected to be orally bioavailable (Table S2). The compounds mapped well with the hydrophobic regions of the binding pocket while their polar chemistry fits with the small hydrophilic regions. Consequently, syntheses of five small ether derivatives were planned: propyl-ether (1c), isopropyl-ether (2c), isobutyl-ether (3c), propargylic-ether (4c), and methyl (cyclopropyl)ether (5c). The role of the bioisosteric change of nitrogen from oxygen was also scrutinized. Thus, propyl amine (6d), isopropyl amine (7d), and methyl (cyclopropyl)-amine (8d) were synthesized.

\subsection{Chemistry}

The synthetic routes to access the target compounds (1-5) c and (6-b) d were based on reported synthetic procedures [45] (Schemes 1-3).

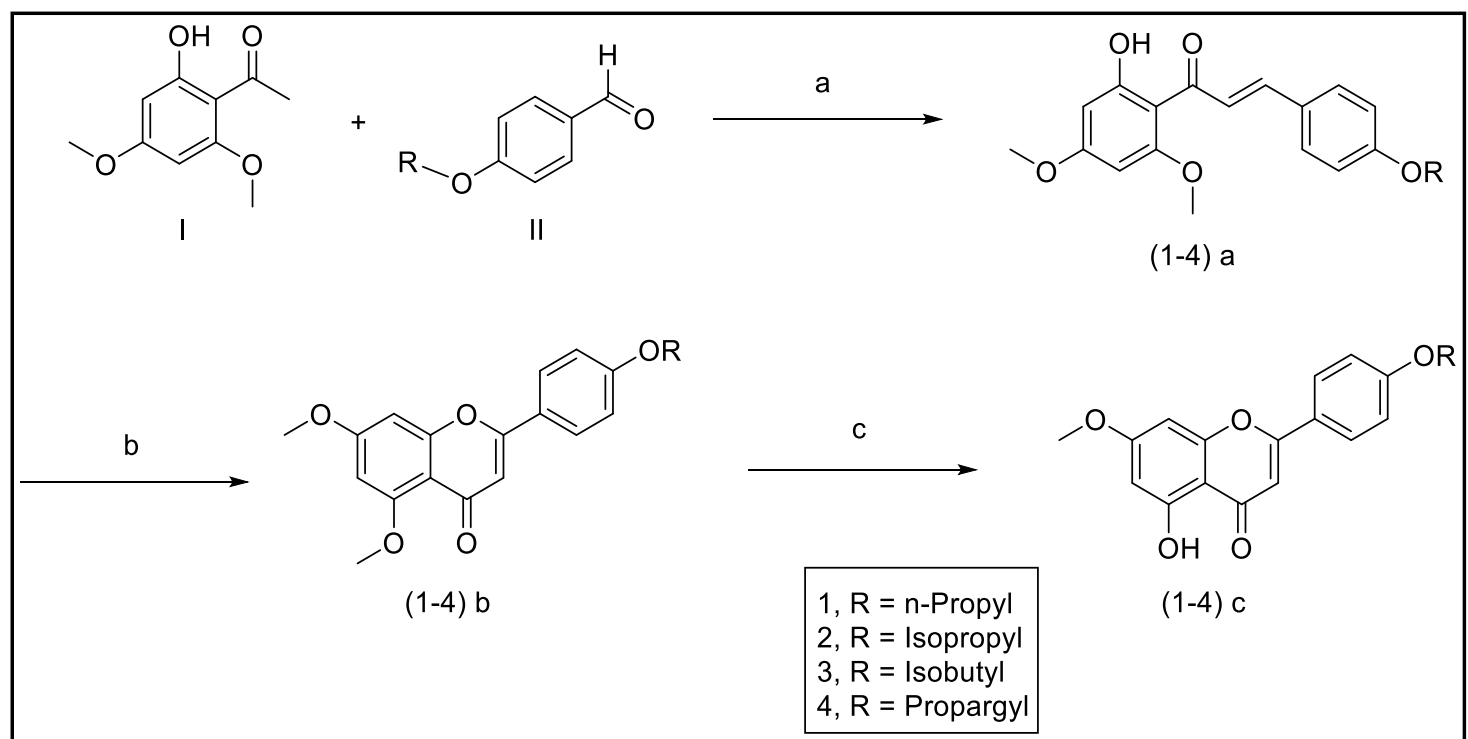

Scheme 1. Reagents and conditions: (a) NaOH 50\%, EtOH, rt, 16-20 h; (b) I, DMSO, $140{ }^{\circ} \mathrm{C}, 4-6$ h; (c) $1 \mathrm{~N} \mathrm{BBr}_{3}, \mathrm{CH}_{2} \mathrm{Cl}_{2}, \mathrm{rt}_{\text {, }}$ 1-3 h. 
<smiles>O=Cc1ccc(O)cc1</smiles>

III<smiles>O=Cc1ccc(OCC2CC2)cc1</smiles>

IV<smiles>COc1cc(O)c(C(C)=O)c(OCCOc2cc(O)c(C(=O)/C=C/c3ccc(OCC4CC4)cc3)c(OC)c2)c1</smiles>

$5 a$<smiles>COc1cc(OC)c2c(=O)cc(-c3ccc(OCC4CC4)cc3)oc2c1</smiles>

$5 b$

Scheme 2. Reagents and conditions: (a) $\mathrm{K}_{2} \mathrm{CO}_{3}$, acetone, reflux; (b) $\mathrm{NaOH} 50 \%, \mathrm{EtOH}, \mathrm{rt}, 16-20 \mathrm{~h}$; (c) $\mathrm{I}_{2}, \mathrm{DMSO}, 140{ }^{\circ} \mathrm{C}, 4-6 \mathrm{~h}$.<smiles>[R]Nc1ccc(-c2cc(=O)c3c(O)cc(OC)cc3oc2=O)cc1</smiles>

Scheme 3. Reagents and conditions: (a) NaOH 50\%, EtOH, rt, 16-20 h; (b) $\mathrm{I}_{2}, \mathrm{DMSO}, 140{ }^{\circ} \mathrm{C}, 4-6 \mathrm{~h}$; (c) $\mathrm{NaOtBu}, \mathrm{Pd} 2(\mathrm{dba})_{3}$, corresponding amines (propylamine, isopropylamine, and (aminomethyl)cyclopropane), BINAP, toluene, $80^{\circ} \mathrm{C}, 48 \mathrm{~h}$; (d) $1 \mathrm{~N} \mathrm{BBr} 3, \mathrm{CH}_{2} \mathrm{Cl}_{2}, \mathrm{rt}, 1-2 \mathrm{~h}$.

\subsubsection{Synthesis of Modified Flavonoids 1-5}

Chalcones (1-4) a were afforded through Schmidt condensation by reacting $2^{\prime}$-hydroxy$4^{\prime}, 6^{\prime}$-dimethoxyacetophenone I and the corresponding 4-benzaldehydes II with $50 \%$ sodium hydroxide in ethanol. Treatment of the chalcones (1-4) with iodine crystals in a minimal amount of DMSO underwent cyclization to yield the dimethoxylated flavonoids (1-4) $\mathbf{b}$. To obtain the target flavonoids (1-4) c, selective demethylation of position C-5 of (1-4) b was accomplished using boron tribromide $\left(\mathrm{BBr}_{3}\right)$ in $\mathrm{CH}_{2} \mathrm{Cl}_{2}$ (Scheme 1).

Compound 5 was prepared as seen in Scheme 2. 4-(cyclopropylmethoxy) benzaldehyde IV was synthesized by reacting (bromomethyl) cyclopropane III with 4-hydroxybenzaldehyde II in acetone and potassium carbonate. Chalcone 5a was prepared through Schmidt condensation by treatment of the cyclopropyl aldehyde IV with $2^{\prime}$-hydroxy- $4^{\prime}, 6^{\prime}$-dimethoxyacet- 
ophenone I and $50 \% \mathrm{NaOH}$ in ethanol. The intermediate flavonoid $\mathbf{5 b}$ was obtained from the treatment of the chalcone with iodine crystals in a minimal amount of DMSO by undergoing cyclization. Several attempts to demethylate position C-5 were unsuccessful, thereby preventing the demethylation at C-5 and releasing the alkyl group to form the hydroxyl group at C- $4^{\prime}$.

\subsubsection{Synthesis of Modified Flavonoids $\mathbf{6}-\mathbf{8}$}

Compounds 6-8 were prepared as shown in Scheme 3 with an extra step involved in the formation of the brominated flavonoid at C $-4^{\prime}$. Thus, the brominated chalcone 6 a was produced by treating 2'-hydroxy-4',6'-dimethoxyacetophenone I with 4-bromobenzaldehyde $\mathrm{V}$ through Schmidt condensation with $50 \%$ sodium hydroxide in ethanol. The brominated flavonoid $\mathbf{6 b}$ was prepared from the treatment of the chalcone with iodine crystals in a minimal amount of DMSO by cyclization. The flavonoids (6-8) c were prepared by treating compound $\mathbf{6 b}$ with sodium tert-butoxide, tris(dibenzylideneacetone) dipalladium, 1,1'-binaphthalene-2,2'-diylbis(diphenylphosphine), and the corresponding amines such as propylamine, isopropylamine, and (aminomethyl)cyclopropane in toluene. Finally, the selective demethylated flavonoids at position 5 (6-8) d were prepared with boron tribromide in dichloromethane (Scheme 3). With the exception of compound $5 \mathbf{c}$, the evaluation of MAO-A and -B inhibition was performed on the final and intermediate compounds.

\subsection{Biological Assays}

3.4.1. Determination of Inhibitory Effects of Modified Flavonoids and Intermediates on MAO-A and -B

The synthesized acacetin 7-O-methyl ether analogs and their intermediates were evaluated against MAO-A and -B inhibition assays. The $\mathrm{IC}_{50}$ values of acacetin 7-O-methyl ether analogs were prominent against MAO-B compared with MAO-A. Flavonoid 3c showed > 3000-fold selective inhibition for MAO-B over MAO-A (Table 2). The significant selectivity obtained for the oxygenated analogs clearly validated our design. Bioisosteric replacement of oxygen with nitrogen at position $C-4^{\prime}$ diminished the selectivity of MAO-B considerably (see Table 2). The presence of the hydroxyl group at C-5 showed increased selectivity towards MAO-B. Thus, the activity and selectivity are increased for the series as follows: hydroxyls at C-5 (1c-4c) > protected-methylated flavonoids at C-5 (1b-6b) > chalcones $(\mathbf{1} \mathbf{a}-\mathbf{6 a})>$ amine flavonoids at C-4 $(\mathbf{6 c}, \mathbf{d}-\mathbf{8 c}, \mathbf{d})$. Compounds (1-4) c exhibited more than a thousand-fold SI (Table 2), equal to or more potent than safinamide (Table 2), and were considered for further studies to understand their mechanisms of inhibition. Figure S76 shows the inhibition dose-response for the potent analogs (1-4) c.

3.4.2. Evaluation of MAO-B Inhibition Kinetics and Analysis of Binding and Time-Dependent Inhibition of Modified Flavonoids (1-4) c

Modified flavonoids (1-4) c were evaluated against MAO-B at varying concentrations of kynuramine, a nonselective substrate, to investigate the nature of inhibition of the enzymes. Based on dose-concentration inhibition, three to five concentrations (below and above the concentration of $\mathrm{IC}_{50}$ values) were selected for the inhibition kinetics experiment. Modified flavonoids (1-4) c inhibited the enzymatic activity of MAO-B with considerably high affinity $\mathrm{Ki}$ at nanomolar units with a range from 43 to $68 \mathrm{nM}$ (Table 3).

Binding of modified flavonoids (1-4) c with human MAO-B affected $K_{m}$ (i.e., the affinity of the substrate for the enzyme) as well as $V_{\max }$ (maximum enzyme activity) values, indicating the type of MAO-B inhibition by the analogs: flavonoid 1c (mixed/partially reversible), 2c (mixed/partially reversible), 3c (mixed/irreversible), and 4c (mixed/irreversible) (Table 3, Figure 7). 
Table 2. Inhibition ( $\mathrm{IC}_{50}$ values) of recombinant human monoamine oxidases $\mathrm{A}$ and $\mathrm{B}$ by acacetin 7-O-methyl ether analogs and intermediates.

\begin{tabular}{|c|c|c|c|}
\hline $\begin{array}{l}\text { Synthesized } \\
\text { Analogs }\end{array}$ & MAO-A $\left(\mathrm{IC}_{50}, \mu \mathrm{M}\right) *$ & MAO-B $\left(\mathrm{IC}_{50}, \mu \mathrm{M}\right) *$ & $\begin{array}{l}\text { Selectivity Index } \\
\text { MAO-A/B }\end{array}$ \\
\hline $1 \mathrm{a}$ & $0.515 \pm 0.024$ & $0.40 \pm 0.024$ & 1.3 \\
\hline $2 a$ & $0.117 \pm 0.05$ & $0.049 \pm 0.0035$ & 2.4 \\
\hline $3 a$ & $0.42 \pm 0.002$ & $0.22 \pm 0.0211$ & 1.9 \\
\hline $4 a$ & $9.42 \pm 1.78$ & $8.33 \pm 0.7871$ & 1.1 \\
\hline $5 a$ & $1.30 \pm 0.09$ & $0.90 \pm 0.035$ & 1.4 \\
\hline $1 b$ & $>100$ & $1.70 \pm 0.076$ & $>58.8$ \\
\hline $2 b$ & $>100$ & $2.64 \pm 0.0880$ & $>37.9$ \\
\hline $3 b$ & $>100$ & $7.23 \pm 2.1438$ & $>13.8$ \\
\hline $4 b$ & $>100$ & $>100$ & $>1$ \\
\hline $4 a$ & $9.42 \pm 1.78$ & $8.33 \pm 0.7871$ & 1.1 \\
\hline $4 b$ & $>100$ & $>100$ & $>1$ \\
\hline $5 b$ & $>100$ & $22.82 \pm 2.098$ & $>4.4$ \\
\hline 1c & $48.78 \pm 2.01$ & $0.033 \pm 0.0042$ & 1478.2 \\
\hline $2 c$ & $30.74 \pm 0.023$ & $0.016 \pm 0.0070$ & 1921.3 \\
\hline $3 c$ & $>100$ & $0.031 \pm 0.0070$ & $>3225.8$ \\
\hline $4 c$ & $62.70 \pm 5.21$ & $0.049 \pm 0.0014$ & 1279.6 \\
\hline $6 a$ & $12.349 \pm 0.249$ & $>100$ & $>0.1$ \\
\hline $6 b$ & $87.830 \pm 5.449$ & $28.407 \pm 2.639$ & 3.1 \\
\hline $6 c$ & $>100$ & $22.097 \pm 2.479$ & $>4.5$ \\
\hline $7 \mathrm{c}$ & $37.492 \pm 0.476$ & $9.447 \pm 0.113$ & 4.0 \\
\hline $8 c$ & $39.095 \pm 5.144$ & $12.727 \pm 0.290$ & 3.1 \\
\hline $6 d$ & $85.484 \pm 1.585$ & $1.554 \pm 0.137$ & 55.0 \\
\hline $7 d$ & $40.500 \pm 2.374$ & $0.417 \pm 0.012$ & 97.1 \\
\hline $8 d$ & $39.114 \pm 0.555$ & $2.185 \pm 0.088$ & 17.9 \\
\hline Acacetin & $0.105 \pm 0.0014$ & $0.042 \pm 0.0021$ & 2.5 \\
\hline $\begin{array}{c}\text { Acacetin 7-O-methyl } \\
\text { ether [11] }\end{array}$ & $>100$ & $0.198 \pm 0.001$ & $>505.05$ \\
\hline Clorgyline & $0.0039 \pm 0.0002$ & $2.15 \pm 0.212$ & 0.002 \\
\hline Deprenyl & $33.00 \pm 1.411$ & $0.046 \pm 0.0014$ & 717.4 \\
\hline Safinamide [46] & $90.00 \pm 2.470$ & $0.060 \pm 0.005$ & 1500.0 \\
\hline Harmine & $0.0031 \pm 0.0003$ & $39.000 \pm 1.412$ & 0.00008 \\
\hline
\end{tabular}

Table 3. Inhibition/binding affinity constant (Ki) values for inhibition of recombinant human MAO-B by modified flavonoids (1-4) c, acacetin, acacetin 7-O-methyl ether, and deprenyl.

\begin{tabular}{ccccc}
\hline Compound & \multicolumn{2}{c}{ Monoamine Oxidase A } & \multicolumn{2}{c}{ Monoamine Oxidase B } \\
Type of Inhibition
\end{tabular}

${ }^{*}$ Values are the mean \pm S.D. of triplicate experiments. 

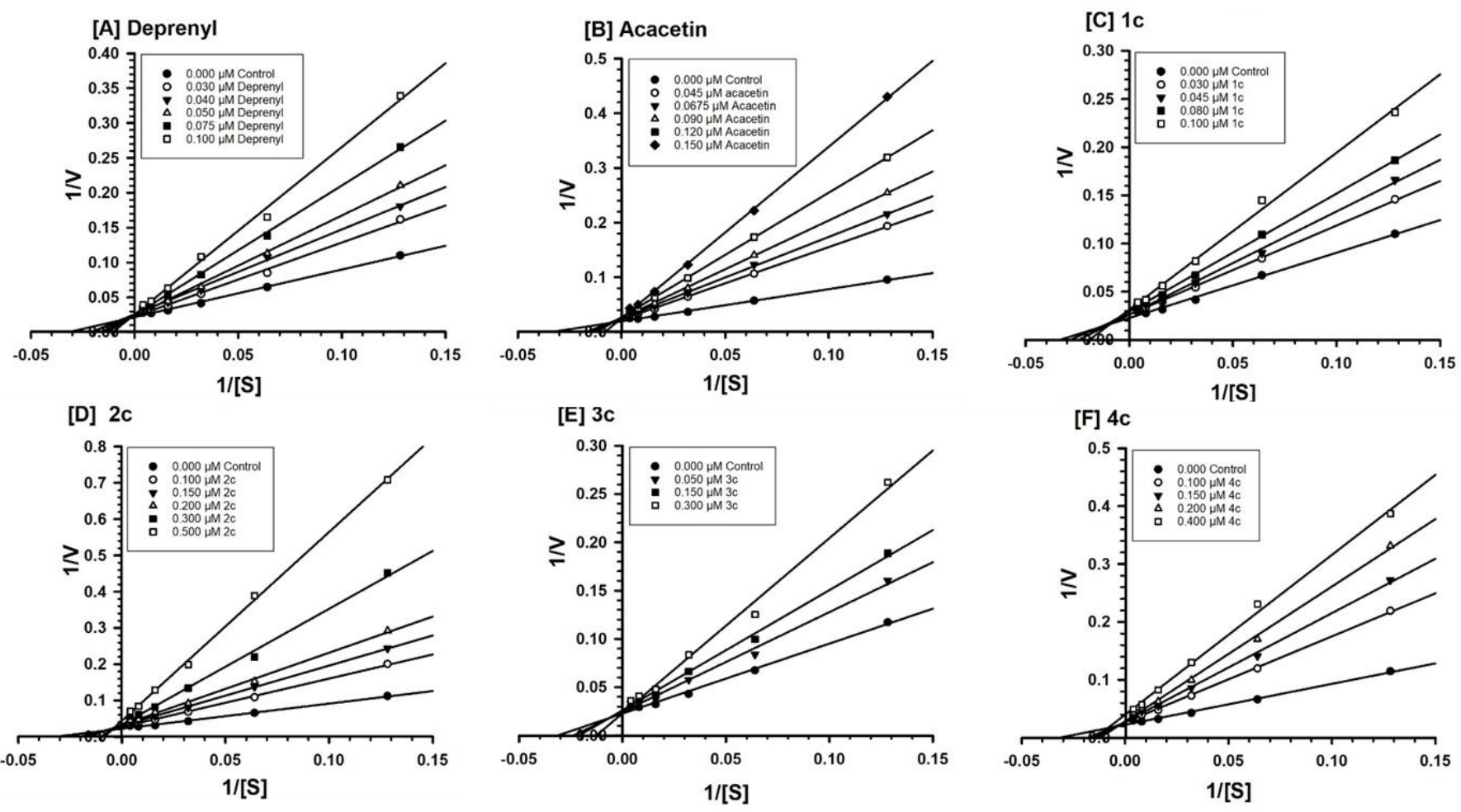

Figure 7. Kinetic characteristics of inhibition of recombinant human MAO-B with [A] deprenyl [B] acacetin, [C] 1c, [D] 2c, [E] 3c, and $[\mathrm{F}] 4 \mathrm{c} ; \mathrm{V}=$ nmoles $/ \mathrm{min} / \mathrm{mg}$ protein and $\mathrm{S}=$ substrate kynuramine concentration $(\mu \mathrm{M})$.

The binding characteristics of the modified flavonoids (1-4) c with MAO-B were examined by equilibrium dialysis to measure the dissociation of the enzyme-inhibitor complex (Figure 8). MAO-B enzyme was incubated with the highest concentration of the analogs for $20 \mathrm{~min}$ at $37^{\circ} \mathrm{C}$ to allow for binding of the inhibitor with the enzyme and formation of the enzyme-inhibitor complex. Then, the mixtures of the enzyme-inhibitor complex were dialyzed overnight at $4{ }^{\circ} \mathrm{C}$ using $25 \mathrm{mM} \mathrm{KHPO}_{4}$ (pH 7.4) buffer. The enzyme activities were examined before and after dialysis. Incubation of MAO-B with $1.5 \mu \mathrm{M}$ of modified flavonoids (1-4) c caused more than $70 \%$ inhibition of activity and only the enzyme activities of $1 \mathrm{c}(30 \%)$ and $2 \mathrm{c}(66 \%)$ were recovered after dialysis. Thus, the binding of $\mathbf{1 c}$ was partially reversible, while $\mathbf{2} \mathbf{c}$ was reversible with MAO-B (Figure 8 , Table 3).

To inspect the time-dependent binding inhibition of MAO-B, the enzyme was preincubated with the analog for 0 to $15 \mathrm{~min}$ at concentrations that caused nearly $40-80 \%$ inhibition depending on the analog (Figure S77). For compounds 1c, 3c, and 4c, 70-80\% inhibition was seen at the concentrations given in Figure S77. Meanwhile, compound 2c showed $30-50 \%$ of MAO-B enzyme inhibition. The control enzyme without inhibitor was also run concurrently. For validation, the MAO- B standards were run simultaneously for the time-dependent assay.

\subsection{Computational Analysis of Enzyme-Inhibitor Interactions for Modified Flavonoids (1-4) $c$}

Based on the remarkable experimental selectivity of MAO-B towards the designed compounds (1-4) c, further computational analysis was conducted. These analogs did not show good docking poses in MAO-A due to the clashes between the R group and the amino acids in the substrate binding site. The size and nature of the $\mathrm{R}$ group are essential for selective targeting. In general, these four acacetin 7-O-methyl ether analogs exploited the hydrophobic nature of the amino acids in the binding pocket of MAO-B, particularly Tyr 398 and Tyr 435, near the FAD cofactor by forming $\pi-\pi$ stacking with their aromatic functionalities. The non-polar nature of the R group matches the hydrophobic nature of the Leu and Ile amino acids on the other side of the binding site. Considerable hydrophobic contacts were observed between the ligands and Leu 167, Leu 171, Ile 199, Tyr 236, and 
Phe 343. The ligands placed properly their polar chemistry to form strong hydrogen bonds with the backbones of Leu 171, Ile 199, and the side chain of Gln 206 (Figure 9). There is room in the binding pocket for water molecules to bridge the interactions between the ligands and amino acids, principally near the FAD.

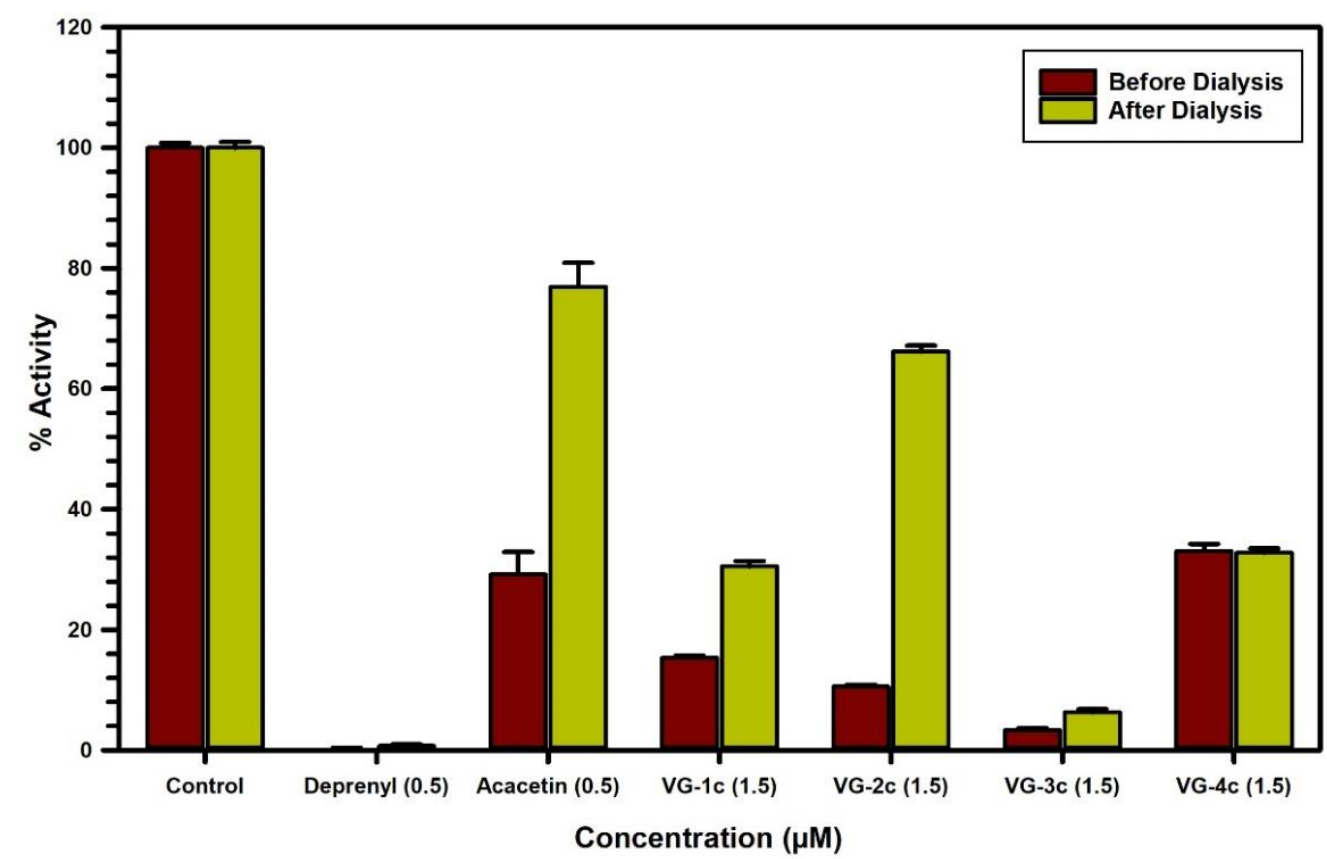

Figure 8. Analysis of the nature of binding of deprenyl $(0.5 \mu \mathrm{M})$, acacetin $(0.5 \mu \mathrm{M}), 1 \mathrm{c}(1.5 \mu \mathrm{M}), 2 \mathrm{c}$ $(1.5 \mu \mathrm{M}), 3 \mathrm{c}(1.5 \mu \mathrm{M})$, and $4 \mathrm{c}(1.5 \mu \mathrm{M})$ with recombinant human MAO-B by recovery of catalytic activity of the enzyme after equilibrium dialysis dissociation. Each bar shows the mean \pm S.D. of triplicate values.

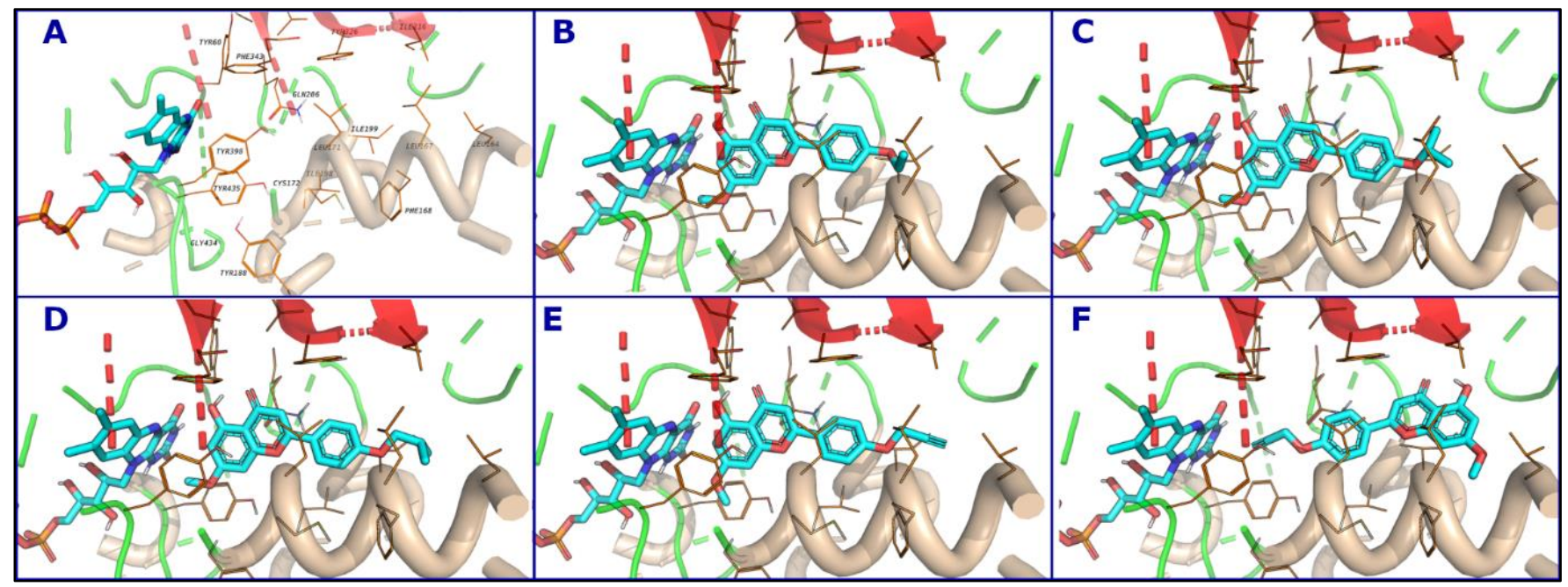

Figure 9. Binding modes of acacetin 7-O-methyl ether derivatives and surrounding amino acids. The amino acids that interact with the ligand are shown as lines (A), Compounds $1 \mathbf{c}(\mathbf{B}), \mathbf{2 c}(\mathbf{C}), 3 \mathbf{c}(\mathbf{D})$, and $4 \mathbf{c}(\mathbf{E}, \mathbf{F})$. There are two possible orientations for $4 \mathrm{c}$ in the binding site.

\section{Conclusions}

Based on our understanding of the SAR of the flavonoid skeleton and the molecular modeling studies, eight flavonoid analogs were designed. All the analogs did not demonstrate acceptable docking poses in the active site of MAO-A but they had good binding 
scores in MAO-B (Table S1). They also fitted well with the thermodynamic properties of the MAO-B active site. The flavonoid compounds with O-propyl, O-isopropyl, $O$-isobutyl, and O-propargyl substituents showed excellent selectivity towards MAO-B, in the range of a 1200- to 3200-fold difference from MAO-A.

Rasagiline and selegiline are FDA-approved irreversible MAO-B inhibitors that exhibited a selectivity of 103- and 127-fold against MAO-A, while safinamide is a reversible MAO-B inhibitor with a selectivity of 1000-1500-fold towards MAO-B [8,9,46]. The synthesized flavonoids $O$-propyl and $O$-isopropyl are reversible MAO-B inhibitors with a selectivity of 1478- and 1921-fold against MAO-A, respectively. O-isobutyl was the most selective of all the synthesized compounds with 3225-fold selectivity towards MAO-B, while $O$-propargyl exhibited 1279 -fold selectivity. $O$-isobutyl and $O$-propargyl were both irreversible MAO-B inhibitors. O-propyl, $O$-isopropyl, $O$-isobutyl, and O-propargyl substituents are potential candidates worth pursuing. Based on the results of these derivatives, (1-4) c with O-alkyl (a short chain with three to four carbon atoms) substituents at position C-4' yield high selectivity toward MAO-B. The nitrogen amine series did not display any significant selectivity towards MAO-B. This could be attributed to the high electronegativity of oxygen compared with nitrogen. The study of the longer alkyl chain on C- $4^{\prime}$ should be explored. It is also worth pursuing the introduction of halogens at position 7 , which might help improve the ADMET properties. Introduction of an electronegative atom such as nitrogen at position 8 would be interesting to understand the SAR of ring $\mathrm{A}$ in MAO activity. Another chemical modification that would help us to understand the activity of MAO-B versus MAO-A in the flavonoid scaffold that is worth exploring is the substitution of the $\mathrm{B}$ ring, introducing $\mathrm{O}$-substituent groups at position $\mathrm{C}-3^{\prime}$ or $\mathrm{C}-4^{\prime}$ as on vetulin or diosmetin (see Table 1), which both show a slight preference towards MAO-B. Flavonoids have limited clinical use due to their significant challenges related to the pharmacokinetic and pharmacodynamic profiles. They have poor oral absorption along with extensive hepatic metabolism and low solubility, thereby resulting in poor bioavailability [12]. Modifying the chemical structure by substituting the flavonoid rings can help overcome the solubility issue. For example, the C-7 position on the A ring can be replaced with fluorine to improve its solubility and bioavailability.

Supplementary Materials: The following are available online at https: / www.mdpi.com/article / 10.3390/biomedicines9101304/s1, Figures S1-S77, and Tables S1 and S2. Additional data, such as ${ }^{1} \mathrm{H}$-NMR spectra, ${ }^{13} \mathrm{C}-\mathrm{NMR}$ spectra, HRMS spectra, and HPLC analysis of compounds 1-8, computational interactions of acacetin and acacetin 7-O-methyl ether and MAO-A and MAO-B, and docking scores and ADME predictions for acacetin 7-O-methyl ether analogs (PDF).

Author Contributions: Synthesis, structural characterization, and manuscript writing, V.G. and F.L.; computational approach and ligand design, M.A.N. and K.M.E.; enzymatic monoamine oxidase inhibition and statistical analysis, N.D.C. and B.L.T.; academic supervision, J.M.R. and S.J.C.; manuscript editing, C.R.M. and S.J.C.; conceptualization, study coordination, and manuscript editing, B.L.T. and F.L. All authors have read and agreed to the published version of the manuscript.

Funding: This research was funded in part by grant numbers P20GM104932 and P30GM122733 from the National Institute of General Medical Sciences (NIGMS), a component of the National Institutes of Health (NIH), and was conducted in part in a facility constructed with support from the Research Facilities Improvements Program (C06RR14503) from the NIH National Center for Research Resources; its contents are solely the responsibility of the authors and do not necessarily represent the official view of the NIGMS or the NIH.

Institutional Review Board Statement: Not applicable.

Informed Consent Statement: No human assay was performed in the present study.

Data Availability Statement: All supporting results are reported in the manuscript. 
Acknowledgments: The authors acknowledge the free academic license granted by Openeye Scientific Software. Some of the results reported in this paper were included in the dissertation submitted by V.G for a Ph.D. in Pharmaceutical Sciences at the School of Graduate Studies, University of Mississippi, University MS 38677. F.L. thanks the College of Pharmacy, University of South Carolina for start-up funds.

Conflicts of Interest: The authors declare no conflict of interest.

\section{References}

1. Scott, L.; Dawson, V.L.; Dawson, T.M. Trumping Neurodegeneration: Targeting Common Pathways Regulated by Autosomal Recessive Parkinson's Disease Genes. Exp. Neurol. 2017, 298, 191-201. [CrossRef] [PubMed]

2. Pringsheim, T.; Jette, N.; Frolkis, A.; Steeves, T.D.L. The Prevalence of Parkinson's Disease: A Systematic Review and MetaAnalysis. Mov. Disord. 2014, 29, 1583-1590. [CrossRef]

3. Blesa, J.; Trigo-Damas, I.; Quiroga-Varela, A.; Jackson-Lewis, V.R. Oxidative Stress and Parkinson's Disease. Front. Neuroanat. 2015, 9, 91. [CrossRef]

4. Sarrafchi, A.; Bahmani, M.; Shirzad, H.; Rafieian-Kopaei, M. Oxidative Stress and Parkinson's Disease: New Hopes in Treatment with Herbal Antioxidants. Curr. Pharm. Des. 2016, 22, 238-246. [CrossRef] [PubMed]

5. Tong, J.; Rathitharan, G.; Meyer, J.H.; Furukawa, Y.; Ang, L.-C.; Boileau, I.; Guttman, M.; Hornykiewicz, O.; Kish, S.J. Brain Monoamine Oxidase B and A in Human Parkinsonian Dopamine Deficiency Disorders. Brain 2017, 140, 2460-2474. [CrossRef] [PubMed]

6. Szökő, É.; Tábi, T.; Riederer, P.; Vécsei, L.; Magyar, K. Pharmacological Aspects of the Neuroprotective Effects of Irreversible MAO-B Inhibitors, Selegiline and Rasagiline, in Parkinson's Disease. J. Neural Transm. 2018, 125, 1735-1749. [CrossRef]

7. Liguori, C.; Stefani, A.; Mercuri, N.B.; Pierantozzi, M. Effective Treatment of Restless Legs Syndrome by Safinamide in Parkinson's Disease Patients. Sleep Med. 2018, 41, 113-114. [CrossRef]

8. Guglielmi, P.; Carradori, S.; Ammazzalorso, A.; Secci, D. Novel Approaches to the Discovery of Selective Human Monoamine Oxidase-B Inhibitors: Is There Room for Improvement? Expert Opin. Drug Discov. 2019, 14, 995-1035. [CrossRef]

9. Chaurasiya, N.D.; Gogineni, V.; Elokely, K.M.; León, F.; Núñez, M.J.; Klein, M.L.; Walker, L.A.; Cutler, S.J.; Tekwani, B.L. Isolation of Acacetin from Calea urticifolia with Inhibitory Properties against Human Monoamine Oxidase-A and -B. J. Nat. Prod. 2016, 79, 2538-2544. [CrossRef] [PubMed]

10. Semwal, R.B.; Semwal, D.K.; Combrinck, S.; Trill, J.; Gibbons, S.; Viljoen, A. Acacetin-A Simple Flavone Exhibiting Diverse Pharmacological Activities. Phytochem. Lett. 2019, 32, 56-65. [CrossRef]

11. Chaurasiya, N.D.; Zhao, J.; Pandey, P.; Doerksen, R.J.; Muhammad, I.; Tekwani, B.L. Selective Inhibition of Human Monoamine Oxidase B by Acacetin 7-Methyl Ether Isolated from Turnera diffusa (Damiana). Molecules 2019, 24, 810. [CrossRef]

12. Amawi, H.; Ashby, C.R., Jr.; Tiwari, A.K. Cancer Chemoprevention Through Dietary Flavonoids: What's Limiting? Chin. J. Cancer 2017, 36, 1-13. [CrossRef]

13. Jin, C.-F.; Wang, Z.-Z.; Chen, K.-Z.; Xu, T.-F.; Hao, G.-F. Computational Fragment-Based Design Facilitates Discovery of Potent and Selective Monoamine Oxidase-B (MAO-B) Inhibitor. J. Med. Chem. 2020, 63, 15021-15036. [CrossRef] [PubMed]

14. Aldrich, C.; Bertozzi, C.; Georg, G.I.; Kiessling, L.; Lindsley, C.; Liotta, D.; Merz, K.M., Jr.; Schepartz, A.; Wang, S. The Ecstasy and Agony of Assay Interference Compounds. J. Med. Chem. 2017, 60, 2165-2168. [CrossRef]

15. Baell, J.B.; Holloway, G.A. New Substructure Filters for Removal of Pan Assay Interference Compounds (PAINS) from Screening Libraries and for Their Exclusion in Bioassays. J. Med. Chem. 2010, 53, 2719-2740. [CrossRef] [PubMed]

16. Sterling, T.; Irwin, J.J. ZINC 15-Ligand Discovery for Everyone. J. Chem. Inf. Model. 2015, 55, 2324-2337. [CrossRef]

17. Chaurasiya, N.D.; León, F.; Ding, Y.; Gómez-Betancur, I.; Benjumea, D.; Walker, L.A.; Cutler, S.J.; Tekwani, B.L. Interactions of Desmethoxyyangonin, a Secondary Metabolite from Renealmia alpinia, with Human Monoamine Oxidase-A and Oxidase-B. Evid. Based Complement. Altern. Med. 2017, 2017, 4018724. [CrossRef]

18. Parikh, S.; Hanscom, S.; Gagne, P.; Crespi, C.; Patten, C. A Fluorescent-Based, High-Throughput Assay for Detecting Inhibitors of Human Monoamine Oxidase A and B. BD Biosci. Discov. Labware 2002, S02T081R2. [CrossRef]

19. Small-Molecule Drug Discovery Suite 2017-4; Schrödinger, LLC.: New York, NY, USA, 2017.

20. Greenwood, J.R.; Calkins, D.; Sullivan, A.P.; Shelley, J.C. Towards the Comprehensive, Rapid, and Accurate Prediction of the Favorable Tautomeric States of Drug-Like Molecules in Aqueous Solution. J. Comput. Aided Mol. Des. 2010, 24, 591-604. [CrossRef]

21. Shelley, J.C.; Cholleti, A.; Frye, L.L.; Greenwood, J.R.; Timlin, M.R.; Uchimaya, M. Epik: A Software Program for $p K_{\mathrm{a}}$ Prediction and Protonation State Generation for Drug-Like Molecules. J. Comput. Aided Mol. Des. 2007, 21, 681-691. [CrossRef] [PubMed]

22. Schrödinger Release 2017-4: Epik; Schrödinger, LLC.: New York, NY, USA, 2017.

23. Harder, E.; Damm, W.; Maple, J.; Wu, C.; Reboul, M.; Xiang, J.Y.; Wang, L.; Lupyan, D.; Dahlgren, M.K.; Knight, J.L.; et al. OPLS3: A Force Field Providing Broad Coverage of Drug-like Small Molecules and Proteins. J. Chem. Theory Comput. 2016, 12, 281-296. [CrossRef] [PubMed]

24. Friesner, R.A.; Murphy, R.B.; Repasky, M.P.; Frye, L.L.; Greenwood, J.R.; Halgren, T.A.; Sanschagrin, P.C.; Mainz, D.T. Extra Precision Glide: Docking and Scoring Incorporating a Model of Hydrophobic Enclosure for Protein-Ligand Complexes. J. Med. Chem. 2006, 49, 6177-6196. [CrossRef] 
25. Halgren, T.A.; Murphy, R.B.; Friesner, R.A.; Beard, H.S.; Frye, L.L.; Pollard, W.T.; Banks, J.L. Glide: A New Approach for Rapid, Accurate Docking and Scoring. 2. Enrichment Factors in Database Screening. J. Med. Chem. 2004, 47, 1750-1759. [CrossRef] [PubMed]

26. Friesner, R.A.; Banks, J.L.; Murphy, R.B.; Halgren, T.A.; Klicic, J.J.; Mainz, D.T.; Repasky, M.P.; Knoll, E.H.; Shelley, M.; Perry, J.K.; et al. Glide: A New Approach for Rapid, Accurate Docking and Scoring. 1. Method and Assessment of Docking Accuracy. J. Med. Chem. 2004, 47, 1739-1749. [CrossRef]

27. Schrödinger Release 2017-4: Glide; Schrödinger, LLC.: New York, NY, USA, 2017.

28. Arul Murugan, N.; Chiotis, K.; Rodriguez-Vieitez, E.; Lemoine, L.; Ågren, H.; Nordberg, A. Cross-interaction of tau PET tracers with monoamine oxidase B: Evidence from in silico modelling and in vivo imagining. Eur. J. Nucl. Med. Mol. Imagining 2019, 46, 1369-1382. [CrossRef] [PubMed]

29. Arul Murugan, N.; Zaleśny, R. Multiscale modeling of two-photon probes for Parkinson's diagnostics based on monoamine oxidase B biomarker. J. Chem. Inf. Model. 2020, 60, 3854-3863. [CrossRef]

30. Arul Murugan, N.; Muvva, C.; Jeyarajpandian, C.; Jeyakanthan, J.; Subramanian, V. Performance of force-field and machine learning-based scoring functions in ranking MAO-B protein-inhibitor complexes in relevance to developing Parkinson's therapeutics. Int. J. Mol. Sci. 2020, 21, 7648. [CrossRef]

31. Schrödinger Release 2017-4: LigPrep; Schrödinger, LLC.: New York, NY, USA, 2017.

32. Elokely, K.M.; Doerksen, R.J. Docking Challenge: Protein Sampling and Molecular Docking Performance. J. Chem. Inf. Model. 2013, 53, 1934-1945. [CrossRef]

33. Bowers, K.J.; Chow, D.E.; Xu, H.; Dror, R.O.; Eastwood, M.P.; Gregersen, B.A.; Klepeis, J.L.; Kolossvary, I.; Moraes, M.A.; Sacerdoti, F.D.; et al. Scalable Algorithms for Molecular Dynamics Simulations on Commodity Clusters. In Proceedings of the SC '06: Proceedings of the 2006 ACM/IEEE Conference on Supercomputing, Tampa, FL, USA, 11-17 November 2006. [CrossRef]

34. Desmond Molecular Dynamics System, D.E. Shaw Research, New York, NY, 2021. Maestro-Desmond Interoperability Tools, Schrödinger, New York, NY. 2021. Available online: https:/ / www.schrodinger.com/ citations (accessed on 12 December 2017).

35. SZMAP 1.2.1.4; OpenEye Scientific Software: Santa Fe, NM, USA. Available online: http:/ / www.eyesopen.com (accessed on 12 December 2017).

36. Bayden, A.S.; Moustakas, D.T.; Joseph-McCarthy, D.; Lamb, M.L. Evaluating Free Energies of Binding and Conservation of Crystallographic Waters Using SZMAP. J. Chem. Inf. Model. 2015, 55, 1552-1565. [CrossRef] [PubMed]

37. Elokely, K.; Velisetty, P.; Delemotte, L.; Palovcak, E.; Klein, M.L.; Rohacs, T.; Carnevale, V. Understanding TRPV1 Activation by Ligands: Insights from the Binding Modes of Capsaicin and Resiniferatoxin. Proc. Natl. Acad. Sci. USA. 2016, 113, E137-E145. [CrossRef]

38. Olsen, H.T.; Stafford, G.I.; van Staden, J.; Christensen, S.B.; Jäger, A.K. Isolation of the MAO-Inhibitor Naringenin from Mentha aquatica L. J. Ethnopharmacol. 2008, 117, 500-502. [CrossRef]

39. Larit, F.; Elokely, K.M.; Chaurasiya, N.D.; Benyahia, S.; Nael, M.A.; León, F.; Abu-Darwish, M.S.; Efferth, T.; Wang, Y.-H.; Belouahem-Abed, D.; et al. Inhibition of Human Monoamine Oxidase A and B by Flavonoids Isolated from Two Algerian Medicinal Plants. Phytomedicine 2018, 40, 27-36. [CrossRef]

40. Baek, S.C.; Park, M.H.; Ryu, H.W.; Lee, J.P.; Kang, M.-G.; Park, D.; Park, C.M.; Oh, S.-R.; Kim, H. Rhamnocitrin Isolated from Prunus padus var. seoulensis: A Potent and Selective Reversible Inhibitor of Human Monoamine Oxidase A. Bioorg. Chem. 2019, 83, 317-325. [CrossRef] [PubMed]

41. Chaurasiya, N.D.; Midiwo, J.; Pandey, P.; Bwire, R.N.; Doerksen, R.J.; Muhammad, I.; Tekwani, B.L. Selective Interactions of O-Methylated Flavonoid Natural Products with Human Monoamine Oxidase-A and -B. Molecules 2020, 25, 5358. [CrossRef] [PubMed]

42. Carradori, S.; Gidaro, M.C.; Petzer, A.; Costa, G.; Guglielmi, P.; Chimenti, P.; Alcaro, S.; Petzer, J.P. Inhibition of Human Monoamine Oxidase: Biological and Molecular Modeling Studies on Selected Natural Flavonoids. J. Agric. Food Chem. 2016, 64, 9004-9011. [CrossRef]

43. Park, S.E.; Paudel, P.; Wagle, A.; Seong, S.H.; Kim, H.R.; Fauzi, F.M.; Jung, H.A.; Choi, J.S. Luteolin, a Potent Human Monoamine Oxidase-A Inhibitor and Dopamine $\mathrm{D}_{4}$ and Vasopressin $\mathrm{V}_{1 \mathrm{~A}}$ Receptor Antagonist. J. Agric. Food Chem. 2020, 68, 10719-10729. [CrossRef] [PubMed]

44. Chaurasiya, N.D.; Ibrahim, M.A.; Muhammad, I.; Walker, L.A.; Tekwani, B.L. Monoamine Oxidase Inhibitory Constituents of Propolis: Kinetics and Mechanism of Inhibition of Recombinant Human MAO-A and MAO-B. Molecules 2014, 19, $18936-18952$. [CrossRef] [PubMed]

45. Chen, H.; Mrazek, A.A.; Wang, X.; Ding, C.; Ding, Y.; Porro, L.J.; Liu, H.; Chao, C.; Hellmich, M.R.; Zhou, J. Design, Synthesis, and Characterization of Novel Apigenin Analogues that Suppress Pancreatic Stellate Cell Proliferation In vitro and Associated Pancreatic Fibrosis In vivo. Bioorg. Med. Chem. 2014, 22, 3393-3404. [CrossRef]

46. Pandey, P.; Chaurasiya, N.D.; Tekwani, B.L.; Doerksen, R.J. Interactions of endocannabinoid virodhamine and related analogs with human monoamine oxidase-A and-B. Biochem. Pharmacol. 2018, 155, 82-91. [CrossRef] 